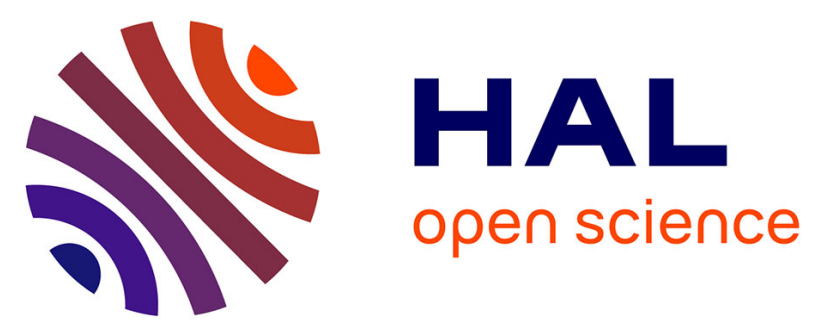

\title{
DO PRODUCT MARKET REGULATIONS IN UPSTREAM SECTORS CURB PRODUCTIVITY GROWTH? PANEL DATA EVIDENCE FOR OECD COUNTRIES
}

Renaud Bourlès, Gilbert Cette, Jimmy Lopez, Jacques Mairesse, Giuseppe

Nicoletti

\section{To cite this version:}

Renaud Bourlès, Gilbert Cette, Jimmy Lopez, Jacques Mairesse, Giuseppe Nicoletti. DO PRODUCT MARKET REGULATIONS IN UPSTREAM SECTORS CURB PRODUCTIVITY GROWTH? PANEL DATA EVIDENCE FOR OECD COUNTRIES. 2010. halshs-00504161

\section{HAL Id: halshs-00504161 \\ https://shs.hal.science/halshs-00504161}

Preprint submitted on 20 Jul 2010

HAL is a multi-disciplinary open access archive for the deposit and dissemination of scientific research documents, whether they are published or not. The documents may come from teaching and research institutions in France or abroad, or from public or private research centers.
L'archive ouverte pluridisciplinaire HAL, est destinée au dépôt et à la diffusion de documents scientifiques de niveau recherche, publiés ou non, émanant des établissements d'enseignement et de recherche français ou étrangers, des laboratoires publics ou privés. 


\title{
GREQAM
}

Document de Travail

Groupement de Recherche en Economie Quantitative d'Aix-Marseille - UMR-CNRS 6579 Ecole des Hautes Etudes en Sciences Sociales Universités d'Aix-Marseille II et III

DO PRODUCT MARKET REGULATIONS IN UPSTREAM SECTORS CURB

PRODUCTIVITY GROWTH? PANEL DATA EVIDENCE FOR OECD COUNTRIES

\author{
Renaud BOURLÈS \\ Gilbert CETTE \\ Jimmy LOPEZ \\ Jacques MAIRESSE \\ Giuseppe NICOLETTI
}

July 2010

n'2010-23

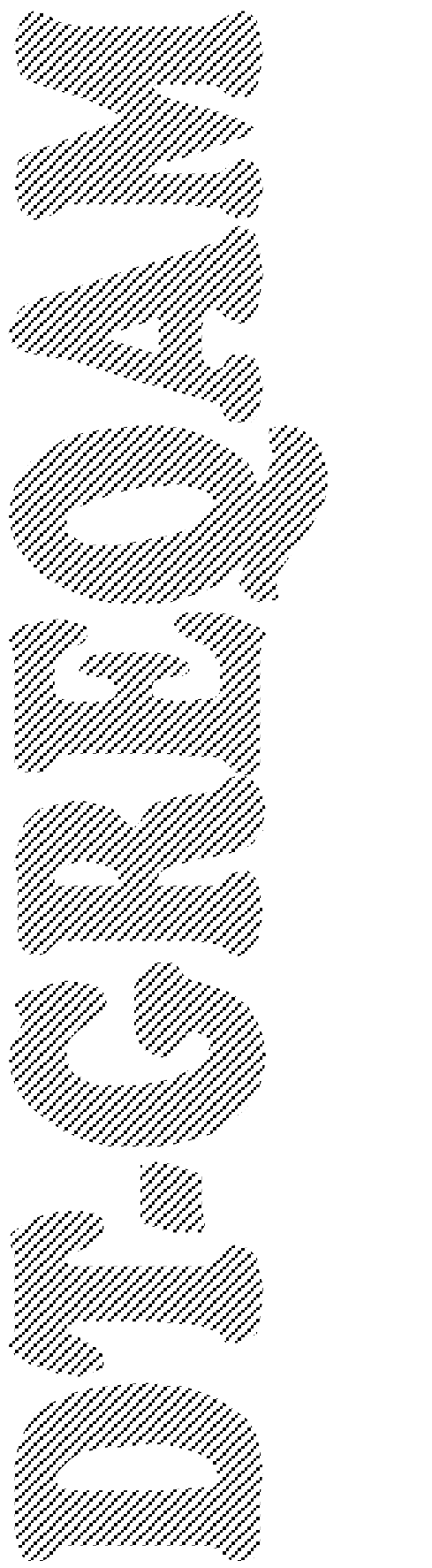




\title{
DO PRODUCT MARKET REGULATIONS IN UPSTREAM SECTORS CURB PRODUCTIVITY GROWTH? PANEL DATA EVIDENCE FOR OECD COUNTRIES
}

\author{
Renaud Bourlès $^{a} \quad$ Gilbert Cette $\quad$ Jimmy Lopez $^{c}$ \\ Jacques Mairesse $\quad$ Giuseppe Nicoletti $i^{e}$
}

a: Ecole Centrale Marseille, GREQAM-IDEP ; renaud.bourles@centrale-marseille.fr

b: Banque de France and Université de la Méditerranée (DEFI) ; gilbert.cette@banque-france.fr

c: Banque de France ; jimmy.lopez@banque-france.fr - Corresponding author

$d$ : CREST-ENSAE and University of Maastricht (UNU-MERIT); Jacques.mairesse@ensae.fr

e :OECD Economics Department; Giuseppe.nicoletti@oecd.org

The authors wish to thank Philippe Aghion for advice at the preparatory stage of this paper and Francesco Daveri for useful comments as well as participants in the OECD-CESifo conference on "Product market regulation: political economy and effects on performance", Munich 29-30 January 2010, and in seminars at the OECD and Banque de France. The views expressed in the paper are those of the authors and do not necessarily reflect those of Banque de France, the OECD or its member countries. 


\begin{abstract}
Based on an endogenous growth model, we show that intermediate goods markets imperfections can curb incentives to improve productivity downstream. We confirm such prediction by estimating a model of multifactor productivity growth in which the effects of upstream competition vary with distance to frontier on a panel of 15 OECD countries and 20 sectors over 1985-2007. Competitive pressures are proxied with sectoral product market regulation data. We find evidence that anticompetitive upstream regulations have curbed MFP growth over the past 15 years, more strongly so for observations that are close to the productivity frontier.
\end{abstract}

Keywords: Productivity, Growth, Regulations, Competition, Catch-up.

JEL classification: O43, L5, O57, L16, C23

\title{
Résumé
}

En s'appuyant sur un modèle de croissance endogène, nous montrons dans cette étude que les imperfections de marché dans les secteurs amont abaissent les incitations à améliorer la productivité en aval. Cette conjecture est confirmée empiriquement par l'estimation d'un modèle qui différencie les effets potentiels, sur la productivité globale des facteurs (PGF), d'une concurrence insuffisante dans les secteurs amont selon la distance à la frontière technologique sectorielle. Ces estimations sont réalisées sur un panel de 15 pays de l'OCDE et 20 secteurs d'activité sur la période 1985-2007. La concurrence en amont est mesurée par des indicateurs sectoriels de régulation sur les marchés des biens. Les résultats montrent que, sur les 15 dernières années, les régulations anticompétitives dans les secteurs amont ont affaibli les gains de PGF, tout particulièrement pour les observations proches de la frontière technologique.

Mots clés : Productivité, Croissance, Régulations, Compétition, Rattrapage.

Codes JEL : O43, L5, O57, L16, C23 


\section{I - Introduction}

Competition -- and policies affecting it -- has been found to be an important determinant of productivity growth in recent empirical research. ${ }^{1}$ Firm-level evidence has generally supported the idea that competitive pressures are a driver of productivity enhancing innovation and adoption (Geroski, 1995a, 1995b; Nickell, 1996; Nickell et al., 1997; Blundell et al., 1999; Griffith et al., 2002; Haskel et al., 2007; Aghion et al., 2004), especially for incumbent firms that are close to the technological frontier (Aghion et al., 2005; Aghion et al., 2006a). Further evidence has also been provided at the industry level (Nicoletti and Scarpetta, 2003; Griffith et al., 2006; Inklaar et al., 2008; Buccirossi et al., 2009) and for aggregate productivity measures (Conway et al., 2006; Aghion et al., 2009) generally based on cross-country panels.

Most empirical studies of the competition-growth link focused on competitive conditions within each sector (or market) as drivers of firm or industry-level productivity enhancements. Yet, to the extent that expected rents from innovation or technology adoption are underlying efforts to improve efficiency relative to competitors, focusing on within-sector competition misses an important part of the story. Indeed, these rents, and the corresponding within-sector incentives to improve productivity, may be reduced by lack of competition in sectors that sell intermediate inputs that are necessary to production. In other words, if there is market power in these upstream sectors and firms in downstream industries have to negotiate terms and conditions of their contracts with suppliers, part of the rents expected downstream from adopting best-practice techniques will be grabbed by intermediate input providers. This in turn will reduce incentives to improve efficiency and curb productivity in downstream sectors, even if competition may be thriving there. Moreover, lack of competition in upstream sectors can also generate barriers to entry that curb competition in downstream sectors as well, further reducing pressures to improve efficiency in these sectors. For example, tight licensing requirements in retail trade or transport can narrow access to distribution channels and overly restrictive regulation in banking and finance can reduce the range of available sources of financing for all firms in the economy.

The influence of competition in upstream sectors for productivity improvements downstream is likely to be particularly relevant in developed countries where most industries are increasingly involved in global competition. In sectors or markets exposed to trade, direct competitive pressures from rival firms (both incumbents and new entrants) are often strong and provide the expected incentives for efficiency improvement. By contrast, several non-manufacturing sectors are often protected from extensive trade pressures by either the need for proximity or the fact that service provision occurs through national physical networks. With these non-manufacturing sectors accounting for rising shares of total intermediate inputs, lack of competition there propagates

\footnotetext{
Theoretically, the link between competition and productivity growth has been traced to three main factors: innovation, technology adoption and reallocation across heterogeneous firms. While some early models of endogenous technical change (Romer, 1990; Grossman and Helpman, 1991; Aghion and Howitt, 1992) would predict competition to curb innovation in line with Schumpeterian theory, more recent analyses (sometimes called neo-Schumpeterian) predict positive or hump-shaped effects of competition on innovation (Aghion and Schankerman, 2004; Aghion et al., 2001). Firm heterogeneity plays an important role in both neo-Schumpeterian theories and models that focus on the positive impact of low market frictions and competitive pressures on reallocation from low to high productivity firms (Melitz, 2003; Bernard et al., 2003; Melitz and Ottaviano, 2008; Restuccia and Rogerson, 2007). Parente and Prescott (1994, 1999) have highlighted more specifically the negative effects of barriers to competition on technology adoption.
} 
throughout the economy by increasing the cost (or reducing the quality) of the services provided to downstream sectors. In turn, the cost of goods produced using these services are also inflated, with a cascading effect on other intermediate inputs. Higher costs (or lower quality) of intermediate inputs indirectly frustrate efforts of firms that purchase these goods and services to improve efficiency in order to escape competition, because the expected returns from such efforts are shrunk. As these returns are higher for firms that compete neck-and-neck with rivals that are close to the technological frontier, lack of competition upstream is likely to reduce downstream incentives to improve efficiency more markedly when distance to frontier is short, as it is often the case in increasingly globalized markets.

Our paper tackles these issues squarely by focusing on the influence of upstream competition for productivity outcomes in downstream sectors. To our knowledge, only a few papers looked at this issue so far, and only in static cross-section analyses relating manufacturing productivity outcomes to measures of competition in services (Allegra et al., 2004; Faini et al., 2006; Barone and Cingano, 2008). Our contribution to this line of research is twofold. First, we provide a full-fledged formalisation of the links between upstream competition and downstream productivity based on an extension of the neo-Schumpeterian endogenous growth model by Aghion et al. (1997). Second, we test the model prediction that lack of upstream competition curbs downstream efficiency improvements by using a stylized version of the dynamic "neo-Schumpeterian" model (Acemoglu et al., 2006) in which rent-seeking efficiency improvements are driven by both improvements at the frontier and the speed of catch up to this frontier, measured by a distance factor. This makes it possible to differentiate the potential downstream effects of lack of upstream competition in situations close and far from the global technological frontier.

We measure industry-level efficiency improvements and distance to frontier through a multifactor productivity (MFP) index. Using OECD industry statistics we construct MFP measures for 15 OECD countries and 20 sectors over the 1984-2007 period. We proxy competition upstream with detailed time series information on policies, rules and regulations that generate entry barriers in key non-manufacturing industries (henceforth called "upstream" industries) and measure the importance of these barriers for all industries that use the non-manufacturing inputs (henceforth "downstream" industries) by means of input-output relationships. ${ }^{2}$ We then match the MFP measures with the timeseries indicators of the indirect burden of anti-competitive regulations in non-manufacturing sectors on each of the 20 sectors covered by our data. We use these data to run panel regressions controlling for a number of unobserved factors and perform extensive robustness checks on the results.

We find clear evidence that anticompetitive regulations in upstream sectors curb MFP growth downstream. Consistent with the neo-Schumpeterian framework, these effects are non linear and depend on distance to frontier. They are strongest for observations (i.e. country/sector/period triads) that are close to the global technological frontier, but remain generally negative for a large share of our data. Interestingly, the share of observations whose MFP growth suffers from anticompetitive regulations increased over time, with the negative indirect effects of regulations

2 Our work is therefore related to the industry-level analysis of Conway et al. (2006) and the firm-level analyses of Arnold et al. (2006) and Forlani (2009). However, Conway et al. focused on labour productivity, an inadequate measure of efficiency improvements, and did not distinguish between effects of competition in upstream and downstream sectors. Arnold et $a l$. and Forlani only looked at the effects of service sector competition on manufacturing MFP outcomes in single countries (Czech Republic and France, respectively) and did not consider the effect of distance to frontier effects. Forlani focused on market-based rather than policy-based measures of upstream competition. 
affecting virtually all observations over the past 15 years. This could be due to increased integration of the world economy in the context of the diffusion of new technologies: with competition correspondingly becoming tougher downstream and adoption becoming more compelling, erosion of innovation rents by regulated upstream sectors is increasingly more damaging for incentives to enhance productivity. Measured at the average distance to frontier and average level of anticompetitive regulations the effect of increasing competition by instantaneously and completely eliminating such regulations is to increase MFP growth by between 1 and 1.5 per cent per year depending on the period covered. This is of course a purely illustrative case because it would represent an unrealistically ambitious reform agenda. More realistic scenarios, in which each country's regulations are aligned on actual best practices suggest smaller but still sizeable yearly gains in MFP growth. Our results are robust to changes in the way MFP is constructed, to the use of different input-output tables for measuring the burden of upstream regulation on downstream sectors, to variations in the sample of countries and/or sectors and to modifications in the set of fixed effects used to account for unobservables.

The paper is organised as follows. In the next section we formalise the link between lack of competition in upstream sectors and efficiency growth downstream extending the "neoSchumpeterian" endogenous growth model of Aghion et al. (1997). We then present the econometric specification (section III) used to test the main prediction of the model. Next, we describe the main features of our MFP and regulation data (section IV). Finally, in section V, we discuss our empirical results and the related robustness checks. In this context, we provide illustrative simulations of the potential effects of policy changes aimed at making upstream markets more competitive. A few reflections on links to previous literature, open issues and directions for future research conclude the paper. Details about model derivations and data construction are provided in the appendix.

\section{II - Upstream market competition and downstream productivity growth: the channels}

A large and growing body of research has studied the effects of competition on growth (see Aghion and Griffith, 2005, for a survey). While competition can affect economic performance through various channels, this line of research has usually focused on the direct effects of lack of competition in a sector on its productivity performance. ${ }^{3}$ In this paper we focus on the effects of regulations that curb market competition in upstream sectors, such as legal barriers to entry in some non-manufacturing markets, (henceforth "anticompetitive upstream regulations") on the productivity performance of downstream sectors.

We highlight two main channels through which lack of competition in upstream sectors can generate trickle-down effects that affect the productivity performance of other sectors. Firstly, anticompetitive regulations in an upstream sector can reduce competition downstream if access to downstream markets requires using intermediate inputs produced upstream, particularly in the case of services inputs where import competition is limited. For example, if financial market regulations narrow the range of available financial instruments or products, access to finance by downstream firms can be made difficult, thereby curbing new entry and firm growth. Similarly, if restrictive

3 For recent surveys, see Griffith and Harrison (2004), Crafts (2006), Schiantarelli (2005) and Nicoletti and Scarpetta (2006). 
licensing or business conduct regulations in trade or transport services hinder the development of open, efficient and innovative distribution channels, market access by downstream firms can suffer, with negative repercussions for productivity growth. Secondly, even if anticompetitive upstream regulations do not restrict market access downstream, they can still curb incentives to improve efficiency in downstream sectors or firms. If markets for intermediate inputs are imperfect, downstream firms may have to negotiate with (and can be held up by) suppliers. In this case, regulations that increase suppliers' market power can reduce incentives to improve efficiency downstream, as part of the (possibly temporary) rents that downstream firms expect from such improvements will have to be shared with suppliers of the intermediate inputs that are necessary for downstream production.

Our theoretical model, drawn from Lopez (2010), highlights these two channels in the following way. First, imperfect competition in upstream sectors makes the search for intermediate input suppliers time-consuming and costly for new downstream firms. Formally, finding a supplier of intermediate input, which is a necessary requirement to start producing, involves a Poisson hazard rate of $\rho<1$. During this search new entrants suffer an instantaneous cost $b$. We assume that the hazard rate $\rho$ is decreasing with the level of upstream competition. This barrier to entry affects the number of downstream producers $N$ through a free-entry condition (the value of new firms is zero at the equilibrium). Second, rent-seeking efficiency incentives in downstream sectors are reduced by the search costs implied by imperfect competition in upstream sectors. These costs provide market power to upstream suppliers, creating a gap between the intermediate input price $p^{I I}$ and the marginal cost $c$ of producing the input, which is assumed to be constant. In this setting, input prices are determined by the sharing of the total product market rents $R$ between upstream and downstream firms, which depends on the power of negotiation of the upstream firms $\beta:\left(p^{I I}-c\right) . l=\beta . R$, with $l$ the quantity of intermediate inputs. We assume that the power of negotiation of the upstream firms is decreasing with the level of competition in the upstream sectors.

We introduce these implications of imperfections in intermediate input markets in a stylized version of the "neo-Schumpeterian" model of Aghion et al. (1997). ${ }^{4}$ We consider an economy composed of a unit mass of identical consumers. Each consumer has an instantaneous utility function: $u()=.\int_{0}^{1} \ln \left(x_{j}\right) d j$ with $x_{j}$ being consumption of final good from industry $j$. Because of the logarithmic utility function each industry receives the same expenditure share. Spending on each final good is normalised to unity: $p_{j} \cdot x_{j}=1 \forall j$. Each final good is produced using intermediate good $l_{j}$ as the only input, according to the production function: $x_{i j}=\gamma^{k i} . l_{i}$, with $x_{i j}$ being the quantity of good $j$ produced by the firm $i$ using a quantity $l_{i}$ of intermediate input, $k_{i}$ the technological level of the firm $i$ and $\gamma$ captures the size of the efficiency improvement steps $(\gamma>1)$. In order to simplify the presentation, the industry indices are omitted from now on.

\footnotetext{
${ }^{4}$ Along with these imperfections, our model differs principally from Aghion et al. (1997) by two other assumptions. In Aghion et al. (1997) only two firms compete on each market and the catch-up probability depends on the follower's effort. In our model the number of downstream firms is endogenous but, in order to keep things tractable, the catch-up probability is exogenous.
} 
Firms can move one technological step ahead at a Poisson hazard rate $\alpha$ by incurring a cost $f(\alpha) .^{5}$ Then catch-up occurs at an exogenous Poisson hazard rate of $\lambda{ }^{6}$ We assume that the largest possible gap between the leader and the follower is one technological step due to knowledge externalities. If the leader innovates, the follower immediately climbs one step up the quality ladder. Consequently, the leader has no incentive to keep innovating. Three types of firms indexed by $i \in\{-1,0,1\}$ may therefore exist: followers $(i=-1)$, leaders $(i=1)$, or firms in a leveled industry $(i=0)$, meaning an industry in which all firms have the same technological level. Firms compete in price. In a leveled industry profits should be equal to zero, but we assume a degree of collusion $\epsilon<1$ between firms, thus the total profit for the industry is equal to $\varepsilon \pi_{1}$, and each firm earns $\pi_{0}=\frac{\epsilon \cdot \pi_{1}}{N}{ }^{7}$ In an unleveled industry, a leader maximizes its profit $\pi_{1}$ by applying a limit pricing rule, setting a price that makes the profit $\pi_{-1}$ of the followers equal to zero, thus grabbing all the expenditure share of its variety.

As already mentioned, the power of negotiation of the upstream suppliers distorts the competition between the leader and the followers by introducing a price-cost gap for the input good, which reduces the leader's profit:

$\pi_{1}=(1-\beta) \cdot\left(1-\frac{1}{\gamma}\right)$

The sequence of decisions is the following. At each instant some firms are exogenously destroyed, at a Poisson hazard rate of $\delta$, and others decide to enter in the downstream market, according to the free-entry condition. The new entrants have to find a supplier of intermediate inputs to be able to produce. ${ }^{8}$ Then these firms have to choose their optimal effort to increase their technology. Finally, output and an input price are determined simultaneously, and then the final goods are sold. The resolution of the model is recursive and is detailed in Appendix 1. The main steps and results are presented below.

The steady state Bellman equations associated to each possible state: leveled $J_{0}$, leader $J_{I}$ and follower $J_{-1}$ can be expressed as:

$r J_{0}=\pi_{0}+\alpha \cdot\left(J_{1}-J_{0}\right)+\bar{\alpha} \cdot\left(J_{-1}-J_{0}\right)-\delta \cdot J_{0}-f(\alpha)$

where $r$ represents the discount rate.

Indeed, if we consider a firm in a leveled industry

- with probability $\alpha$, this firm innovates and become a leader,

\footnotetext{
${ }^{5}$ In order to have a positive equilibrium rate of efficiency improvements we assume: $\frac{\partial \mathrm{f}(\alpha)}{\partial \alpha}>0, \frac{\partial^{2} \mathrm{f}(\alpha)}{\partial \alpha^{2}}>0 \lim _{\alpha \rightarrow 0} \frac{\partial \mathrm{f}(\alpha)}{\partial \alpha}=0$, $\lim _{\alpha \rightarrow+\infty} \frac{\mathrm{f}(\alpha)}{\alpha}=+\infty$ and $\lim _{\alpha \rightarrow+\infty} \frac{\alpha \cdot \partial \mathrm{f}(\alpha) / \partial \alpha}{\mathrm{f}(\alpha)}>1$.

${ }^{6}$ In other words, the efficiency improvement of the leader is protected from catch-up for a period of expectancy $1 / \lambda$.

${ }^{7}$ We assume that $\varepsilon$ is exogenous, even though it is likely that collusion would be increasingly hard to achieve as the number of firms increase. Accounting for this effect would strengthen our conclusions.

${ }^{8}$ When catch-up happens, firms previously followers must also find a supplier of intermediate inputs and they are impacted by the free-entry condition as the new entrants.
} 
- with probability $\bar{\alpha}$, another firm innovates (by symmetry $\bar{\alpha}=(N-1) \alpha$ ), and

- with probability $\delta$, the firm is destroyed

Similarly

$r J_{1}=\pi_{1}+\lambda \cdot\left(J_{0}-J_{1}\right)-\delta \cdot J_{1}$

and

$r J_{-1}=\pi_{-1}+(\lambda+\delta) \cdot\left(J_{0}-J_{-1}\right)-\delta \cdot J_{-1}$

as the technological leader is caught up by followers with probability $\lambda$ and destroyed with probability $\delta$.

The downstream firms in a leveled industry choose the rate of efficiency improvements that maximise their value:

$\frac{\partial f\left(\alpha^{*}\right)}{\partial \alpha}=J_{1}-J_{0}=\frac{\pi_{1}-(1-\Omega) \cdot\left(\pi_{0}-f(\alpha)\right)}{r+\delta+\lambda+\alpha \cdot(1-\Omega)}$

with $\Omega(\alpha) \equiv \frac{\bar{\alpha}}{r+2 \delta+\lambda+\bar{\alpha}}$ is the risk of being overtaken in a leveled industry.

At the downstream firm optimum the marginal cost of efficiency improvements equals the expected gains from the improvements. These gains, i.e. the incentives for efficiency improvements, are growing with the level of competition downstream, as the profit in a leveled industry is decreasing with the number of downstream producers. For a given number of downstream producers, the incentives are also growing with the leader's profit. ${ }^{9}$

Firms enter the downstream markets until the value of a new entrant is higher than the entry cost:

$r V=\rho . J_{0}-b=0$

with $V$ the value of a new entrant searching for a supplier of intermediate inputs.

This free-entry condition -- along with equations (1), (2) and (3) -- determines the level of competition on the downstream market, i.e. the number of firms:

$J_{0}=\frac{1-\Omega}{r+\delta} \cdot \frac{\alpha \cdot \pi_{1}+(r+\delta+\lambda) \cdot\left(\pi_{0}-f(\alpha)\right)}{r+\delta+\lambda+\alpha \cdot(1-\Omega)}=\frac{b}{\rho}$

9 The incentives for efficiency improvements are also increasing with the risk of being overtaken in a leveled industry. As this risk depends itself on the rate of efficiency improvements it could lead to multiple equilibrium or corner solution. We assume that the cost of efficiency improvements increases fast enough to avoid this possibility (see Appendix 1). 
Equations (4) and (5) define the equilibrium values of the rate of efficiency improvements and of the number of downstream producers. Whereas there is no explicit solution for the last, the rate of efficiency improvements is given by the following equation:

$\frac{\partial f\left(\alpha^{*}\right)}{\partial \alpha}=\frac{\pi_{1}-(r+\delta) \cdot b / \rho}{r+\delta+\lambda}$

where $b / \rho$ is the expected cost of finding an intermediate input supplier.

The model has the following implications: ${ }^{10}$

- The number of downstream firms is inversely related to the expected cost (i.e. time) of finding an intermediate input supplier. In turn, stronger competition downstream increases the incentives to efficiency improvements by reducing profits in leveled industries, i.e. by increasing the gap between pre and post-innovation rents.

- The bargaining power of upstream firms reduces incentives to efficiency improvements because it decreases the leader's expected profit by distorting the competition with followers.

- It is natural to assume that, as competitive pressures increase in upstream markets, the bargaining power of intermediate goods suppliers and the expected cost for a downstream firm to find a supplier falls (because either the hazard rate or the search cost falls, or both).

- With easier access to suppliers and higher expected profits from becoming a leader, incentives to improve efficiency increase for downstream firms.

Therefore, the main prediction of the model is that weak upstream competition can curb efficiency growth in downstream firms. The remainder of this paper is devoted to test this prediction by means of an econometric specification that accounts for both this upstream regulation-downward efficiency link and some of the other determinants of efficiency growth already highlighted in the literature (the technological pass-through and the technological catch-up). As explained later in detail, to this end we proxy efficiency with industry-level MFP and lack of competitive pressures in upstream markets with the extent of industry-level anti-competitive regulations. These are measured by the OECD indicators of sectoral barriers to entry generated by product market policies. We further define as "upstream sectors" those non-manufacturing sectors for which the OECD provides data on such barriers to entry and we define as "downstream sectors" all sectors in the economy that source intermediate inputs from such regulated sectors (including the regulated sectors themselves). The properties of the specification tested in the empirical investigation and the data used in the empirical analysis are described in the next two sections.

10 Note that, since catch up by followers is assumed to be exogenous, the relationship between competition and efficiency improvements is non-linear, as the effect is nil for followers and positive for firms that are neck-and-neck. However, the model cannot yield the sort of inverted U-curve highlighted in Aghion et al. (2005). This limitation of the innovation model however is not crucial for the purposes of our analysis. 


\section{III - The econometric specification and its long-term properties}

\subsection{The econometric specification}

Recent models of endogenous growth often include the feature that, with technology flows unfettered across countries, productivity growth in follower countries or industries is a positive function of growth at the world technological frontier and of the gap between this frontier and the productivity level of the follower country or industry (e.g. Acemoglu et al., 2006; Aghion and Howitt, 2006). In other words, countries and industries lagging behind the technological frontier can enhance their productivity by adopting leading technologies available on the market (the technological catchup phenomenon). Thus, productivity growth depends on both the ability to catch up and the ability to innovate, with the importance of the latter increasing as the country or industry gets closer to the world frontier (Aghion and Howitt, 1998 Ch. 8). ${ }^{11}$ According to this line of research, anticompetitive regulations mainly influence the productivity of existing firms by altering the incentives to adopt the leading technologies available in the market and innovate. ${ }^{12}$

Interestingly, in these models the aggregate impact of (domestic or foreign) competition on productivity can be non-linear and depends on the characteristics of incumbent firms (e.g. on the degree of firm heterogeneity). Two sets of effects influence the behaviour of productivity in each market, the "escape competition" or "escape entry" effects on the one hand and the Schumpeterian or "discouragement" effects on the other. The prevalence of one set of effects over the other will affect the link between competition and productivity. In turn, this prevalence is determined, among other things, by the average distance to frontier of firms in the market. For instance, the positive "escape competition" or escape entry" effects on incumbents' efforts to improve productivity is likely to be stronger in markets where a large proportion of firms is neck-and-neck and close to frontier than in markets where a large proportion of firms have a wide technological gap to fill (Aghion et al., 2004; Aghion et al., 2006b). Indeed, in markets dominated by firms that are far enough from the world frontier, the Schumpeterian or discouragement effects due to an increase in competition can be strong enough to deter any innovation activity. Therefore, anticompetitive regulations can have differential aggregate effects on productivity in different countries and industries depending on specific technological and market factors, such as the average position of firms relative to frontier production techniques (Askenazy et al., 2008).

Our empirical analysis accounts for the different effects on productivity described so far. It uses regulation data that are explicitly designed to account for the trickle down effects of anticompetitive upstream regulations on the productivity performance of downstream sectors and we use an econometric specification of productivity that allows for the effects of regulation to depend on distance to the technological frontier. The empirical model also allows for persistent heterogeneity in productivity levels and growth across countries and industries, with productivity levels and growth in follower country-industry pairs driven by developments at the global technology frontier. Productivity growth in follower country-industry pairs is a function of both growth at the frontier and the catch-up to frontier productivity levels. Hence, the model can be thought of as an empirical implementation of the "neo-Schumpeterian" growth framework described above. It has been used extensively in recent

11 Griffith et al. (2004) show, that follower countries that invest in R\&D reap a double dividend: they improve both their ability to innovate and their ability to incorporate frontier technologies into the production process.

12 The effects of competition through increased capital formation have been studied empirically by Alesina et al. (2005). 
empirical research on the determinants of productivity growth at both the firm level (e.g. Aghion et al., 2005) and industry level (Nicoletti and Scarpetta, 2003; Conway et al., 2006; Griffith et al., 2006).

Multi-factor productivity for a given country-industry pair $c s$ at time $t\left(M F P_{c s t}\right)$ is modelled as an auto-regressive distributed lag ADL $(1,1)$ process in which the level of MFP is co-integrated with the level of MFP of the frontier country-industry pair Fs. Formally,

$$
\ln M F P_{c s, t}=\alpha_{0} \ln M F P_{c s, t-1}+\alpha_{1} \ln M F P_{F s, t}+\alpha_{2} \ln M F P_{F s, t-1}+\alpha_{3} R E G_{c s, t-1}+\gamma_{s}+\gamma_{c, t}+\varepsilon_{c s, t}
$$

where $M F P_{c s, t}$ is the MFP level of a non-frontier country-industry pair $c s, M F P_{F s t}$ is the MFP level at the technological frontier $F$ for industry $s$ at time $t, R E G_{c s, t}$ is the indicator of the trickle down effects of anticompetitive upstream regulations in each sector/country/period triad, and $\gamma_{s}, \gamma_{c, t}$ are sector and country-year fixed effects, respectively; $\varepsilon_{c s, t}$ is a random error term. Under the assumption of long-run homogeneity $\left(\alpha_{0}+\alpha_{1}+\alpha_{2}=1\right)$, the $\operatorname{ADL}(1,1)$ process in equation (6) has the following Error Correction Model (ECM) representation:

$\Delta \ln M F P_{c s, t}=\alpha_{1} \Delta \ln M F P_{F s, t}+\left(1-\alpha_{0}\right) \ln \left(\frac{M F P_{F s, t-1}}{M F P_{c s, t-1}}\right)+\alpha_{3} R E G_{c s, t-1}+\gamma_{s}+\gamma_{c, t}+\varepsilon_{c s, t}$

This ECM representation has many attractive statistical properties and a straightforward interpretation. ${ }^{13}$ Productivity growth of country-industry pair $c s$ is expected to increase with productivity growth of the industry frontier $F s$ and with the country-industry pair distance from the industry frontier. ${ }^{14}$ The model implies heterogeneity in equilibrium MFP levels because the innovation potential of each country-industry pair is assumed to be only a fraction of the innovation potential at the frontier, and convergence to the frontier takes time.

In keeping with the "neo-Schumpeterian" view of the effects of competition on productivity growth, our regressions also allow for a non-linear effect of anticompetitive upstream regulation on different country-industry pairs by interacting the regulation variable with distance to frontier. Therefore, the following regression model is the baseline specification in our empirical analysis:

$$
\Delta \ln M F P_{c s, t}=\alpha_{1} \Delta \ln M F P_{F s, t}+\left(1-\alpha_{0}\right) g a p_{c s, t-1}+\alpha_{3} R E G_{c s, t-1}+\alpha_{4} R E G_{c s, t-1} \bullet g a p_{c s, t-1}+\gamma_{s}+\gamma_{c, t}+\varepsilon_{c s, t}
$$

where $\operatorname{gap}_{c s, t}=\ln \left(\frac{M F P_{F s, t}}{M F P_{c s, t}}\right)$ is the country-industry pair distance from the industry frontier.

Throughout our analysis, the focus will be set on the total effects of anticompetitive upstream regulations, i.e. $\alpha_{3}+\alpha_{4}$ gap. It should be stressed that if $\alpha_{3}<0$ and $\alpha_{4}<0$ regulation has negative effects on productivity growth that are increasing with distance to frontier, while if $\alpha_{3}<0$

13 See Hendry (1996) for the statistical properties of the ECM model.

14 Notice that, even though the ECM representation is estimated with MFP growth as the dependent variable, the underlying $\mathrm{ADL}(1,1)$ model is in productivity levels and not in growth rates because productivity growth at the industry frontier is not estimated (see Bond et al. 2003). 
and $\alpha_{4}>0$ the negative effects decrease with distance to frontier. In other words, only in the latter case results would be consistent with the neo-Schumpeterian view that lack of competition is more damaging for country-industry pairs that are close to frontier and that compete neck-and-neck with their global rivals.

\subsection{The long-term properties}

It is useful to analyse the steady-state properties of the empirical model. To do this, we first characterize MFP growth at the technological frontier. As gap $\mathrm{F}_{\mathrm{Fs}, \mathrm{t}}=0$, we obtain via relation (7):

$\Delta \ln \mathrm{MFP}_{\mathrm{Fs}, \mathrm{t}}=\frac{\alpha_{3}}{1-\alpha_{1}} \mathrm{REG}_{\mathrm{Fs}, \mathrm{t}-1}+\frac{\gamma_{\mathrm{s}}+\gamma_{\mathrm{F}, \mathrm{t}}}{1-\alpha_{1}}$

At the technological frontier, MFP growth depends: (i) positively on the effects of the sector-specific $\left(\gamma_{\mathrm{s}}\right)$ and the country/time-specific $\left(\gamma_{\mathrm{F}, \mathrm{t}}\right)$ technical progress ; (ii) negatively (if $\alpha_{3}<0$ ) on the effects of anti-competitive regulations in the upstream sectors $\left(\mathrm{REG}_{\mathrm{Fs}, \mathrm{t}-1)}\right)$.

At the steady-state, the distance to the technological frontier $\left(\mathrm{gap}_{\mathrm{cs}, \mathrm{t}-1}\right)$, the anticompetitive regulations $\left(\mathrm{REG}_{\mathrm{Fs}, \mathrm{t}-1}\right)$, the effects of the technical progress $\left(\gamma_{\mathrm{s}}, \gamma_{\mathrm{F}, \mathrm{t}}\right)$, and the MFP growth $(\Delta \mathrm{ln}$ $\mathrm{MFP}_{\mathrm{Fs}, \mathrm{t}}$ ) are constant. Therefore, the steady-state distance to frontier for any follower country is:

$$
\operatorname{gap}_{\mathrm{cs}}=\frac{1}{\left(1-\alpha_{0}+\alpha_{4} \cdot \mathrm{REG}_{\mathrm{cs}}\right)}\left[-\alpha_{3}\left(\mathrm{REG}_{\mathrm{cs}}-\mathrm{REG}_{\mathrm{Fs}}\right)-\left(\gamma_{\mathrm{c}}-\gamma_{\mathrm{F}}\right)\right]
$$

Thus, at the steady-state, the distance to the technological frontier $\left(\mathrm{gap}_{\mathrm{cs}}\right)$ is decreasing with the difference between the country and the frontier effect of the technical progress $\left(\gamma_{\mathrm{c}}-\gamma_{\mathrm{F}}\right)$; and increasing with the difference between the country and the frontier regulation level $\left(\mathrm{REG}_{\mathrm{cs}}-\right.$ $\left.\mathrm{REG}_{\mathrm{Fs}}\right){ }^{15}$

Relation (7) indicates that MFP growth is increasing with the distance to the technological frontier $\left(\mathrm{gap}_{\mathrm{cs}, \mathrm{t}-1}\right)$ under the assumptions of footnote 15 . Hence, if from a steady-state situation a random shock moves the MFP of a country/sector and alters the distance to the technological frontier, this distance will consequently converge to its equilibrium value expressed by relation (8).

\section{IV - Data}

In order to investigate empirically we need data on: the extent of anti-competitive regulation in a sub-set of industries that we define as "upstream"; the importance of these industries as suppliers of intermediate inputs; and multifactor productivity (MFP). Merging different sources we were able to

\footnotetext{
15 Assuming that the distance to frontier has a positive impact on MFP growth and the effect of anticompetitive regulation on MFP growth is negative and decreases with the distance to frontier $\left(0<\alpha_{0}<1, \alpha_{3}<0\right.$ and $\left.\alpha_{4}>0\right)$.
} 
assemble a cleaned unbalanced panel of 4629 observations for 15 countries and 20 industries over the 1984-2007 period. ${ }^{16}$ The data sources and specific calculations are presented below.

\subsection{Product market regulation}

Empirical research on the effects of competition on productivity has used a variety of approaches to measure competitive pressures. These include indicators of market structure and/or market power, survey-based assessments of the business environment and indicators of product market policies. The measures used in this paper try to address three major issues: minimize endogeneity bias, account for the trickle down effects of competitive pressures in upstream industries on downstream industries and provide a link with policies that affect competition.

Addressing the endogeneity of competition measures has been one of the main empirical challenges in trying to identify the impact of competition on innovation or productivity outcomes. Traditional indicators of product market conditions, such as mark-ups or industry concentration indices, can hardly be treated as exogenous determinants of economic outcomes. ${ }^{17}$ Entry of new (possibly foreign) firms is also most likely not exogenous to productivity outcomes. Moreover, research shows that some widely-used indicators of market structure or market power are not univocally related to product market competition. ${ }^{18}$ Finally, these indicators fail to provide a direct link to policy or regulation.

To address these concerns, the empirical analysis reported in the next section is based on some of the potential policy determinants of competition, rather than on direct measures of it. Griffith et al. (2006) and Aghion et al. (2006) have recently taken a similar approach. However, while they focus on EU data on anti-monopoly cases and the implementation of the Single Market Programme, we use indicators of product market regulations drawn from the OECD international product market regulation database. ${ }^{19}$ Moreover, we focus on regulation in non-manufacturing industries and on the trickle down effects of inappropriate regulations in these industries on all sectors of the economy. ${ }^{20}$ The non-manufacturing sector is undoubtedly the most regulated and sheltered part of the economy, while few explicit barriers to competition remain in markets for manufactured goods of OECD economies. Moreover, as suggested by our theoretical model even low-regulated industries can suffer

16 The cleaning method is presented in Appendix 2. As MFP growth at the technological frontier is an explanatory variable it cannot be used also as a dependent variable. Observations for the country-sector frontier are, therefore, excluded from the estimation sample in each period.

17 Amongst the very few cross-country studies that explore the role of competition for productivity, Cheung and Garcia Pascual, (2001) use mark-ups and concentration indexes. At the single-country level, Nickell (1996), Nickell et al. (1997), Blundell et al. (1999) and Disney et al. (2000) use a variety of market indicators to capture competitive pressures. The potential problem of endogeneity of market shares and mark-ups is even more serious at firm-level as firms that have high productivity may gain market shares and enjoy innovation rents. Additional problems specific to market shares and concentration indices are that they depend on precise definitions of geographic and product markets (i.e. the relevant market where competition unfolds) and tend to neglect potential as well as international competition.

18 Boone (2000a, 2000b) suggests that there may be a hump-shaped relationship between competition and mark-ups. Some authors have addressed this issue by using related indicators of relative profits and profit persistence (Creusen et al., 2006; Greenhalgh and Rogers, 2006).

19 The data are publicly available at www.oecd.org/eco/pmr.

20 For similar approaches see Faini et al. (2006), Conway et al. (2006) and Barone and Cingano (2008). 
from regulation-induced market power and inefficiencies in non-manufacturing because all industries are heavy intermediate consumers of non-manufacturing inputs.

\section{a. Non manufacturing regulation indicators}

The OECD indicators of non-manufacturing regulation measure to what extent competition and firm choices are restricted where there are no a priori reasons for government interference, or where regulatory goals could plausibly be achieved by less coercive means. They are based on detailed information on laws, rules and market and industry settings and cover energy (gas and electricity), transport (rail, road and air) and communication (post, fixed and cellular telecommunications), retail distribution and professional services, with country and time coverage varying across industries. In addition this study uses the indicator of restrictions to competition in banking constructed by de Serres et al. (2006).

The main advantages of using these indicators in empirical analysis is that they can be held to be exogenous to productivity developments and that they are directly related to underlying policies, a feature that measures of competition based on market outcomes and business survey data do not have. ${ }^{21}$ Another advantage is that, as they are composite constructs based on detailed information about policies, they address multicollinearity problems in estimation. At the same time, they make it possible to focus on the specific aspects of policies that are thought to be relevant for productivity. Yet another advantage of the OECD indicators is that they vary over countries, industries and time, though full time variability is limited to a subset of non-manufacturing industries. ${ }^{22}$

Figure 1 shows the evolution of non-manufacturing regulation over time as well as their variability over the country-industry dimension. The box plot suggests relatively low time variability over the 1975-1985 period, with a marked downward trend and increased variability over the subsequent period. The cross-country dispersion is narrower at the beginning and end of period, while it increases over the 1985-2003 period. By contrast, variability in the country and industry dimensions remains relatively wide throughout the sample period. Relatively restrictive regulations prevailed at beginning of period in most countries and industries; a movement towards de-regulation started at the beginning of the $80 \mathrm{~s}$, but at different paces in different countries and industries; and a marked convergence in policies characterized the end of period.

\section{b. Regulatory burden indicators}

Using the data on upstream non-manufacturing regulation, we construct indicators of the trickle down effects of such regulation for 20 sectors that use the outputs of these non-manufacturing industries as intermediate inputs. For brevity, these indicators will henceforth be called "regulatory

21 Of course, endogeneity cannot be completely ruled out with these indicators if, for instance, policies are affected by productivity outcomes through political economy channels. On the relative advantages of policy-based and survey-based composite indicators see Nicoletti and Pryor (2005).

22 Indicators for energy, transport and communication cover 30 OECD countries over the 1975-2007 period; the indicators for retail distribution and professional services cover 30 OECD countries for 1998, 2003 and 2007; the indicator for banking covers 30 OECD countries for 2003. As a result, while in the cross-section dimension the indicators cover most of the regulated sectors and countries, time variability of the indicators originates mostly in policy changes in the energy, transport and communication sectors. 
burden" (or REG) indicators. In each country $c$, we compute them for the 1984-2007 period, using information from input-output tables in the following way (see appendix 2 for details):

$$
R E G_{c k t}=\sum_{j} N M R_{c j t} \bullet w_{c j k} \quad 0<w_{c j k}<1
$$

where the variable $N M R_{c j t}$ is an indicator of anti-competitive regulation in non-manufacturing sector $j$ at time $t$ and the weight $w_{c j k}$ is the total input requirement of sector $k$ for intermediate inputs from nonmanufacturing sector $j$. All indicators take continuous values on a scale going from least to most restrictive of private governance and competition. ${ }^{23}$ In order to illustrate how product market reforms change the values of the regulatory burden indicators, a 'best practice' indicator is defined for each sector and year corresponding to a situation in which non-manufacturing regulations are set at the average of the three most liberal countries in the sample. This best practice benchmark is later used to perform simple simulations of the estimated effects of product market reforms on MFP.

To minimize endogeneity issues and measurement error, the indicators of regulatory burden used in empirical analysis are based on the 2000 US input-output table (i.e. we set $w_{c j k}=w_{U S j k}$ for any c). As a result, the empirical specification is a variant of the difference-in-difference approach in which, inter alia, we identify the effects of regulation on productivity using the variability in the intensity of use of regulated intermediate inputs across downstream sectors. Ideally, to fully control for endogeneity the input-output table should come from a country not included in the sample and without any anti-competitive regulation in non manufacturing sectors. The sensitivity analysis shows that estimation results are robust to the exclusion of US from the sample or the use of the input-output table of the UK, a country missing from our sample and where regulation is estimated to be close to best practice in many non manufacturing sectors (see Appendix 3).

Figure 2 shows the sample average by country of the regulatory burden indicators in 1985 , 2000 and 2007 as well as the 2000 and 2007 industry average, and corresponding best practice. The changes over-time reflect the history of non-manufacturing regulation and de-regulation in the countries covered by the sample. In spite of the convergence in policies at the end of the period important cross-country differences remain in 2007. A switch to best practice corresponds to a pervasive and important easing of anticompetitive regulations in every non-manufacturing sector covered in our data set. It is therefore an extreme example of structural policy reform.

\subsection{Productivity}

We measure industry-level efficiency improvements and distance to frontier by means of a multifactor productivity (MFP) index. Using OECD industry statistics we construct MFP measures for 15 OECD countries and 20 sectors over the period 1984-2007.

23 Conway and Nicoletti (2006) provide a detailed description of the indicators of non-manufacturing regulation and the corresponding indicators of "regulatory burden"; Appendix 2 illustrates their main features. 
MFP growth is calculated as follow:

$$
\Delta \ln M F P_{c s, t}=\Delta \ln V A_{c s, t}-\alpha_{s} * \Delta \ln L_{c s, t}-\left(1-\alpha_{s}\right) * \Delta \ln K_{c s, t}
$$

where $V A$ is value added in constant price, $\alpha$ the output elasticity of labour, approximated by the labour share on value added, $L$ total employment, in number of persons, and $K$ the net capital stock in constant price. ${ }^{24}$ Data on value added and total employment come from the STAN database for industrial analysis, net capital stock from the OECD Productivity database by industry (PDBi). ${ }^{25}$

The index of distance to frontier ( $\mathrm{gap}$ ) depends on MFP levels. These levels are calculated for a base year (2000) and then extended over the sample period using data on MFP growth. To ensure comparability across countries, value added and capital stock are converted into prices denominated in a common currency using OECD aggregate purchasing power parities (PPP) ${ }^{26}$ and a common labour share is used, i.e. the industry specific average share over all countries and periods. Estimates are robust to the choice of country or year specific labour shares and to the use of industry specific PPPs for value added (see Appendix 3). ${ }^{27}$ Another comparability issue is raised by the value added prices of the "Electrical and optical equipment" industry, which include communication and computing equipment. In this industry, US prices are not comparable with others because of the extensive use of the hedonic method, with an important impact on estimations. We therefore replaced US hedonic prices in this industry by total manufacturing value added prices (see Appendix 3 for details).

Figure 3 shows the cross-country/cross-industry dispersion of the resulting MFP estimates in selected years. It suggests that variability has been wide over the sample period. On the whole, the leading country MFP has been 1.55 times higher than the median MFP. This median ratio is stable over time, with dispersion around it shrinking over the 1990-1995 and 2003-2007 periods.

\section{V - Empirical results}

Table 1 presents OLS regression results for different specifications of our regression model. Column 1 reports results omitting the interaction between the gap and the regulatory burden indicator, while column 2 is the estimate of our baseline equation (7) including the interaction term. The last two columns report results from the same equation splitting the sample into two sub periods To better

24 Ideally MFP should be calculated using data on hours worked and capital services. However, at the time of writing comprehensive cross-country data on hours worked and capital services were only available for the aggregate economy and estimates of MFP at lower levels of aggregation must be computed using total employment and capital stocks.

25 The construction of the PDBi net capital stocks series is described in Appendix 2 and more information are available in the "PDBi Methodological Notes".

26 Although this implies the assumption of identical comparative price levels across industries, van Biesebroeck (2004) finds that, overall, aggregate PPPs perform as well as sectoral PPPs, where performance is measured as the correlation with sectoral deflators. For some service sectors aggregate PPPs are found to perform better than sectoral PPPs, while for some manufacturing sectors sectoral PPPs perform marginally better (see Appendix 3). In view of this, using aggregate PPPs seems a reasonable approximation, at least for the set of advanced countries in our sample, where shifts in relative prices across sectors are not extreme over the period covered by the analysis.

27 Industry specific PPPs for value added are calculated from the EUKLEMS industry database of PPPs on gross output as well as the input-output tables and PPPs on input from OECD, according to Inklaar et al. (2008). 
compare specifications and always interpret the coefficient on each variable as the mean effect on MFP growth (even in the presence of the interaction term), the technology-gap variable and the indicator of regulatory burden are centred on the sample mean. ${ }^{28}$ To reduce omitted variable bias and control for idiosyncratic country-wide factors, we always include industry and country-time fixed effects. For example, country-time fixed effects account for (possibly time-varying) country-specific characteristics of labour or financial markets, while industry effects account for (time invariant) structural differences in technology or skills across industries.

In our sensitivity analysis we checked for the presence of specific industries, countries or years that would influence significantly the overall results. This could reflect, for instance, different technological features or simply measurement errors. We also estimated the same equations using different definitions of MFP and estimates of the regulatory burden indicators based on different sets of input-output tables. On the whole, the results presented in Table 1 are robust to these changes in the sample and definition of variables (see Appendix 3 for more details).

Our empirical specification of MFP is corroborated by the data. MFP growth in the productivity leader of the industry is always found to have a positive and highly significant influence on productivity growth in less productive countries and sectors, indicating a significant rate of technological pass-through. In addition, the coefficient of the technology-gap variable is estimated to be positive and significant in all specifications, suggesting that, within each industry, countries that are further behind the technological frontier experience higher rates of productivity growth. In other words, catch-up is found to play an important role as a driver of productivity growth, consistent with previous empirical research in this area.

Turning to our main result, the indicator of regulatory burden is found to curb MFP growth and increasingly so the closer MFP is to the technological frontier. When estimated at its mean, our regulatory burden indicator seems to have no significant effect on downstream productivity growth. However, taking into account its indirect influence through the rate of technological catch up, this lack of significance appears to come mainly from a composition effect. Regressions including the interaction term indeed show that the burden of anticompetitive regulation in upstream sectors has a significant effect on MFP growth downstream (as reflected by the tests of joint significance). Moreover, since the coefficient of the interaction term is generally positive and significant $\left(\alpha_{4}>0\right)$, the depressing effect of anti-competitive upstream regulation on MFP growth is significantly stronger for country/sector/period triads that operate close to the technological frontier of our sample.

The estimated effects of anticompetitive upstream regulation, as measured by the indicator of regulatory burden, are consistent with the implications of our neo-Schumpeterian model of the effects of upstream competitive pressures on downstream productivity performance. When regulation restricts competition in sectors that supply intermediate inputs, the incentives to improve efficiency are weaker in downstream sectors the more intensively these sectors use the regulated products. This is because access to intermediate suppliers is limited and the expected (temporary) rents from improving MFP are likely to be (at least partially) captured by market power in upstream sectors. Consistently, our estimates show that anticompetitive regulation in upstream sectors curbs MFP growth downstream. Moreover, these effects are non linear and are strongest for observations that are

28 If the variables were not centred, the coefficient on the regulatory burden indicator would correspond - when the interaction term is present - to the effect of regulation at the frontier (i.e. when the technology-gap is null). 
close to the global technological frontier. In other words, the "escape competition" effect dominates close to the frontier whereas this effect is weakened by a "discouragement" effect far from the frontier consistent with Aghion and Howitt (2006). ${ }^{29}$

Interestingly, regulatory burdens appear to have played an increasingly damaging role for MFP over time, with the strongest damage being observed over the most recent period. Indeed, when the sample is split into two sub-periods (Table 1, columns 3 and 4) the share of observations whose MFP growth suffers from anticompetitive regulation in upstream sectors is estimated to increase substantially over time. Indeed, while the average impact of the regulatory burden indicator is estimated to be positive and non-significant in the 1985-94 period, it becomes negative and significant over the period 1995-2007. At the same time, the attenuating effect of the gap on the MFP impact of regulatory burdens is more than halved in the most recent period.

Figure 4 illustrates these results graphically. It plots the impact of our indicator of regulatory burden on MFP growth against the level of the technology-gap (we show values of the gap expressed in both log-differences and percentage MFP ratios). As this effect depends on the level of regulation, we represent this relationship for three regulatory settings in non-manufacturing industries corresponding to the first, fifth and last decile of the distribution of our indicator of regulatory burden. The slope of these "isoregulation" lines flattens out as regulation becomes more precompetitive(the line coincides with the horizontal axis when there are no anticompetitive regulations at all). Panel A illustrates results for the whole sample period, while panels B and C illustrate those for the two subperiods. On the whole sample, the regulatory burden from upstream sectors curbs productivity downstream for more than $85 \%$ of the observations (and curbs it significantly for about $50 \%$ of the observation). The effect of regulation becomes positive only for a relatively small share of the observations, ${ }^{30}$ whose MFP levels are less than half those of the technology leader, roughly corresponding to the last decile of the distribution of MFP gaps in our sample. Measured at the average gap (64\% of MFP of the technology leader) and average level of regulation (a value of 0.15 for our regulatory burden indicator), the effect of increasing competition in upstream sectors by instantaneously eliminating all anticompetitive regulations is to increase MFP growth by over 1 per cent per year. The results from splitting the sample into two sub-periods translate graphically into a substantial flattening of the relationship between the impact of regulation on MFP growth and the technology gap at each level of the regulatory burden (Figure 4, Panels B and C). In other words, while regulation could have had a positive effect on MFP for a large part of the sample (63\%) over the first sub-period (but significantly so for only $17 \%$ of the observations), it has had a negative effects for virtually all observations (99\%) and significantly so for $73 \%$ of the observations over the 1995-07 period. During this period, an easing of regulatory burdens from their average level (0.14) to zero (i.e. by eliminating all anticompetitive regulations in upstream sectors) would have increased MFP growth of a country with an average MFP ratio of $65 \%$ by up to 1.7 percentage points per year. It should be stressed that these estimated effects are purely illustrative as they would correspond to radical and sudden changes in regulatory settings that are unlikely to be politically implementable in practice. More realistic simulation scenarios are described in the next section.

29 Near the technological frontier small MFP improvements (through innovation or other means) can generate large returns from getting temporarily ahead of neck-and-neck rivals. For instance, close to frontier an innovator may be able to create a new variety and enjoy temporary market power on the market for the new product. Such returns cannot be expected far from frontier, where only substantial improvements can give a temporary advantage on competitors. Thus upstream rigidities lower incentives to improve efficiency at the frontier to a larger extent than far from frontier.

30

This effect is significantly positive for only $3 \%$ of the sample. 
The increasingly negative impact of regulation on MFP growth over time needs to be investigated further, but one interpretation is related to two sources of structural change affecting the global economy during this period: globalisation and the diffusion of new technologies. With increased integration of the world economy in the context of the diffusion of new technologies, competition has become tougher downstream and ICT adoption and the corresponding reorganization of production processes have become more compelling for maintaining market shares. At the same time, new entry by innovative firms has become a more important source of productivity improvements. Thus, the erosion of returns from efficiency improvements by regulated upstream sectors is increasingly more damaging for incentives to enhance productivity, and possible barriers to entry generated by regulation in upstream sectors are increasingly reflected in a drag on industry-level productivity performance. It is important to note that these different effects of regulation depending on the period studied, should not be understood as coming from different levels of development as the effects appear to change over time at each given level of technological gap. They therefore necessarily originate from structural changes in the global economy.

Both our baseline estimates of the MFP growth equation and our empirical findings concerning the effects of upstream regulation are considerably robust to changes in data coverage and variable definitions. The main sensitivity checks included (i) dropping sectors or countries one by one, (ii) basing computation of the REG indicator on the I-O matrix of a different country (or countryspecific I-O matrices) and (iii) changing assumptions in the construction of the MFP index. Variants in MFP construction included applying sectoral instead of national PPPs and using different measures for the labour share. We also adjusted the MFP index for possible bias in the computation of productivity originating from cross-country differences in employment rates and working time (Bourlès and Cette, 2007) and replicated most of the results using labour productivity growth as the dependent variable. Finally, we checked robustness to changes in the definition of prices in the "electrical and optical equipment" (ISIC 30-33) sector, where changes in quality were particularly important over the estimation period. Annex 3 reports detailed results obtained through these robustness analyses. Overall, the size and significance of coefficient estimates are not much affected. $^{31}$

\section{VI - Estimated impact on MFP growth of easing regulation in upstream sectors}

To further illustrate the influence of regulatory burdens on MFP performance, we propose a calculation of the MFP gains in the non-farm business sector from adopting, in the year 2000, the best practice regulation which was observed in upstream sectors in 2007. As already mentioned, for the purposes of this exercise best practice is defined, in each upstream sector, as the average of the three lowest levels of regulation observed among the countries in the dataset (global best practice corresponding to best practice in all upstream sectors). Figure 5 (Panel A) suggests that, in 2000, the degree of anticompetitive regulation in upstream sectors differed considerably among countries.

31 One exception is when using sector-specific output prices for the 30-33 sector in the US, in which case the interaction term loses significance and the negative effects of upstream regulation become linear. Since this is likely to reflect the extensive use of hedonic pricing only in this country, the baseline estimation uses instead global manufacturing output prices in this sector for the US. In any case, results remain unchanged if the relevant US observations are dropped from the dataset or if the US hedonic price index is used to deflate output in the 30-33 sector in all countries. 
Regulation was friendliest to competition in Sweden, Australia, the Netherlands and the United States, while it was most restrictive in France, Austria, Italy and Greece, with cross-country differences originating mainly from transport (ISIC 60-63) and utilities (ISIC 40-41) sectors. ${ }^{32}$ Seven years later (Panel B), cross-country differences persisted despite some convergence, with Denmark, Sweden, the Netherlands and Australia now being the four countries where regulation was friendliest to competition and France, Italy, Austria and Greece continuing to be the most restrictive. From 2000 to 2007, easing of anticompetitive regulations was widespread in the utility sectors and in post and telecommunications (ISIC 64), with remaining differences across countries in 2007 concentrated essentially in the regulation of transport, business services (ISIC 71-74) and wholesale and retail trade (ISIC 50-52). The gap with our measure of global best practice remained sizeable in all countries over the whole period, though it declined over time.

To calculate the potential productivity gains from adopting best practice regulations, we use estimates of equation (3) above as reported in the last column of Table 1 (i.e. the estimates over the 1995-2007 period). In these calculations, the indicator of regulatory burden (REG) is based on domestic input-output matrix, since no endogeneity issue is likely to arise over a seven-year period. Each country-sector-year MFP is projected dynamically: the MFP impact of deregulation results from the initial decrease in the indicator of regulatory burden obtained by adopting best practice regulations in upstream sectors and on the subsequent reductions in distance to frontier (gap) that this initial policy shock sets off over the projection period. ${ }^{33}$ Results of these projections are shown in Figures 67.

In 2007, average productivity gains (in the non-farm business sector) from reforms that were assumed to be made in 2000 range from around 3 to around 13 percentage points depending on the country (Figure 6, Panel A). Cross-country differences in productivity gains reflect four factors: (i) the excess regulatory burden relative to best practice in each upstream sector, (ii) the intensity of downstream intermediate consumption of products from regulated upstream sectors, (iii) the initial distance to frontier of productivity in downstream sectors, (iv) a composition effect due to the weights of each sector in the economy. The largest the excess regulatory burden and intermediate consumption of regulated products the strongest the gains in productivity from aligning regulations in upstream sectors on best international practice; conversely, the smallest the distance to frontier the strongest the gains from deregulation. Relatively strong gains in Austria, Belgium and Italy and relatively weaker gains in Denmark, the Netherlands and Sweden reflect the influence of these opposing forces. Moreover, the annual MFP gains are generally decreasing over the years (Figure 7), with a peak in $2001 .^{34}$ The subsequent decline in annual gains reflects the contraction of the MFP gap set off by deregulation, which implies a declining catch-up effect on MFP, as well as, to a smaller extent, the reduction of the regulatory burdens during the 2000-2006 period in the baseline situation (see figures 2 and 5).

32 Cross-country differences are measured by using standard errors.

33 For this calculation a measurement of the gap in MFP in each country-sector-year triad is necessary. Since our dataset is unbalanced due to some missing data points for capital stocks, the missing gaps in MFP were estimated in the following way: (i) available gaps in MFP were regressed on labor productivity gaps and (ii) the missing gaps in MFP were estimated using these regression results and the labour productivity gaps, which are available for all country-sector-year triads in our sample. The regression was carried out by OLS, with fixed effects for years, sectors and countries $\left(\mathrm{R}^{2}=0.60\right)$.

34 No gains are obtained in 2000, since we assume in the model that regulations have an impact on MFP growth with a one year lag. 
The MFP gains from aligning regulation on best practice simultaneously in all upstream sectors are slightly superior to the aggregate gain obtained from adopting best practices in each of the upstream sectors one by one (Figure 6, Panel A). The differences come from the fact that adopting the best practice in one upstream sector modifies distance to frontier (the MFP gap) in the following years, which modifies in itself the MFP gains obtained by adopting the best practice in other upstream sectors. Given that the resulting differences are minor, the time sequence of sectoral reforms would not appear to be very important. Looking at the bang-for-the-buck of adopting best practices in each upstream sector (Figure 6, Panel B), the highest productivity gains originate from reforms in retail trade and the professional services, while the lowest gains are obtained from adopting best practices in financial intermediation and communication. Of course, this partly reflects the already high degree of homogeneity in regulatory practices in these sectors in year 2000.

\section{VII - Conclusion}

Regulations that bridle access to otherwise competitive markets and unnecessarily constrain business operation can be a drag on productivity growth. While most analyses of this issue have focused on the effects of these regulations on the productivity of the firms or sectors directly concerned, the main point of this paper is that such regulations can also have powerful indirect depressing effects on the productivity of other sectors through input-output interlinkages. We modelled the main channels through which these effects may happen - reduced access to key intermediate inputs and rent-seeking by intermediate input providers that reduces incentives to improve productivity downstream. We then tested the existence and estimated the magnitude of such effects on a sectoral panel of OECD countries over the last two decades. Although our empirical productivity specification cannot distinguish among the various channels at work, we find that differences in regulation of non-manufacturing sectors providing intermediate inputs are indeed quite relevant in explaining the variance of multifactor productivity growth rates in our sample, with upstream regulation curbing such growth rates significantly in a large share of observations. Moreover, we showed that the closer MFP is to the technological frontier the higher is the estimated negative impact of upstream regulation on productivity growth. Interestingly, the estimated negative impact has increased over time in concomitance with deepening globalisation and diffusion of ICT. Over the 1995-2007 period, measured at the average gap, eliminating all regulatory burdens in upstream sectors would have increased MFP growth by up to 1.7 percentage points per year. This is a significant drag on economic performance given that most of OECD countries' GDP growth over the recent past has been driven by growth in multifactor productivity, which generally ranged between 0 and 3 per cent per year.

The need to find ways to boost GDP growth is particularly important in the recovery from the current recession. The implementation of structural reforms aiming at decreasing anticompetitive regulations may be one of them. As suggested in this paper, the MFP gains obtained from such reforms could improve significantly potential output growth, thereby also facilitating the adjustment of public finances, which have suffered from the crisis and the ensuing recovery plans. The simulations we have performed show that all countries could expect important MFP growth gains from structural reforms that consist of adopting best regulation practices in sectors that are important providers of intermediate inputs to the economy. However, these MFP growth gains are different across countries. The differences stem from four factors: (i) the excess regulatory burden relative to 
best practice in upstream sectors, (ii) the intensity of linkages between upstream and downstream sectors, (iii) the weight of sectors in the economy (iv) and the distance of productivity in those sectors to the global productivity frontier. The larger the excess regulatory burden, the higher the intermediate consumption of regulated products, the greater the sectoral composition effect, and the smaller the distance to the productivity frontier, the stronger the gains in productivity from aligning regulations in upstream sectors with best international practice.

More work needs to be done to check the soundness of the policy recommendations drawn from our econometric results. The statistical significance of these results needs to be confirmed by further investigation, and the underlying economic mechanisms have to be better understood. In particular, it would be desirable to better identify statistically the channels through which upstream regulation affects productivity such as those highlighted in our illustrative theoretical model. Progress to bridge better and more precisely the gap between our results and policy implications could be made in the two interrelated dimensions of data and empirical and theoretical modeling. The data dimension is perhaps the most important. In this paper we have taken advantage of the updated OECD data base of regulation indicators, and we can expect further progress from such source of information, in particular as its coverage is extended, as well as by careful comparison with other existing data bases and sources of relevant information. As concerns modeling, more detailed research, ranging from econometric analysis to case studies, investigating the various channels through which specific regulations affect firm behaviour is necessary. As our results suggest a clear link between regulation and productivity over the past 15 years, focusing on the consequences of ICT diffusion in the context of worldwide globalization, and exploring what could be the aftermath of the current economic crisis, would also be essential to deepen our economic understanding of this link. 


\section{References}

Acemoglu, D., P. Aghion and F. Zilibotti (2006), "Distance to Frontier, Selection and Economic Growth", Journal of the European Economic Association, Vol. 4(1), pp. 37-74.

Aghion, P., P. Askenazy, G. Cette, N. Dromel and R. Bourlès (2009), "Education, market rigidities and growth," Economics Letters, Vol. 102(1), pp. 62-65.

Aghion, P., N. Bloom, R. Blundell, R. Griffith and P. Howitt (2005), "Competition and Innovation: An Inverted U Relationship." Quarterly Journal of Economics, May, pp. 701-728.

Aghion, P., R. Blundell, R. Griffith, P. Howitt, and S. Prantl (2006a), "The Effects of Entry on Incumbent Innovation and Productivity”, CEPR Discussion Paper No. 5323.

Aghion, P., R. Blundell, R. Griffith, P. Howitt, and S. Prantl (2004), "Entry and Productivity Growth: Evidence From Microlevel Panel Data." Journal of the European Economic Association, April-May, 2(2-3). pp. 265-276.

Aghion, P., R. Burgess, S. Redding and F. Zilibotti (2006b), "The Unequal Effects of Liberalization: Evidence from Dismantling the License Raj in India", CEPR Discussion Paper No. 5492.

Aghion, P. and R. Griffith (2005), "Competition and Growth", the MIT Press, Cambridge, Massachusetts.

Aghion, P., C. Harris, P. Howitt and J. Vickers (1997), "Competition and Growth with Step-by-Step Innovation: An Example", European Economic Review, Papers and Proceedings, 771-782.

Aghion, P., C. Harris, P. Howitt and J. Vickers (2001), "Competition, Imitation and Growth with Step-by-Step Innovation", Review of Economic Studies, 68, 467-492.

Aghion, P. and P. Howitt (1992) "A Model of Growth through Creative Destruction", Econometrica, vol. 60(2), pp. 323-351.

Aghion, P. and P. Howitt (1998), "Endogeneous Growth Theory”, Cambridge, Mass. The MIT Press.

Aghion, P. and P. Howitt (2006), "Joseph Schumpeter Lecture: Appropriate Policy Growth: A Unifying Framework", Journal of the European Economic Association 4, No. 2-3, pp. 269-314.

Aghion, P. and M. Schankerman (2004), "On the Welfare Effects and Political Economy of Competition-Enhancing Policies", Economic Journal, 114, pp. 804-834.

Alesina, A., S. Ardagna, G. Nicoletti and F. Schiantarelli (2005), "Regulation and Investment", Journal of the European Economic Association, Vol. 3, No. 4 (June), pp. 791-825.

Allegra, E., M. Forni, M. Grillo and L. Magnani (2004), “Antitrust Policy and National Growth: Some Evidence from Italy”, Giornale degli Economisti e Annali di Economia, Vol. 63 (1), pp. 69-86.

Arnold, J., B. Javorcik and A. Mattoo (2006), "Does Services Liberalization Benefit Manufacturing Firms?," CEPR Discussion Papers No. 5902.

Askenazy P., C. Cahn and D. Irac (2008), "Competition, R\&D and the Cost of Innovation", PSE Working Papers 2008-32, PSE (Ecole normale supérieure). 
Barone G. and F. Cingano (2008), "Service regulation and growth: evidence from OECD countries", Temi di discussione (Economic working papers) 675, Bank of Italy, Economic Research Department.

Bernard, A., J. Eaton, J.B. Jensen and S. Kortum (2003), "Plans and Productivity in International Trade", American Economic Review, 93(04), pp. 1268-1290.

Blundell, R., R. Griffith and J. Van Reenen (1999), "Market Share, Market Value and Innovation in a Panel of British Manufacturing Firms", Review of Economic Studies, 66, pp. 529-554.

Bond, S., J. Elston, J. Mairesse and B. Mulkay (2003), "Financial Factors and Investment in Belgium, France, Germany, and the United Kingdom: A Comparison Using Company Panel Data", The Review of Economics and Statistics, 85(1), pp. 153-165.

Boone, J. (2000a), "Competition", Center Discussion Paper No. 2000-104, Tilburg University, Netherlands, October.

Boone, J. (2000b), "Competitive Pressure: The Effects on Investments in Product and Process Innovation", RAND Journal of Economics, Vol. 31, No. 3, pp. 549-569.

Bourlès, R. and G. Cette (2005), "A comparison of structural productivity in the major industrialized countries”, OECD Economics Studies, N²1, pp. 75-107.

Bourlès, R. and G. Cette (2007), "Trends in "structural" productivity levels in the major industrialized countries", Economics Letters, Vol. 95(1), pp. 151-156.

Buccirossi, P., L. Ciari, T. Duso, G. Spagnolo and C. Vitale (2009), "Competition Policy and Productivity Growth: An Empirical Assessment", CEPR Discussion Papers No. 7470.

Cheung, W. and A. Garcia Pascual (2001), "Market Structure, Technology Spillovers, and Persistence in Productivity Differentials", CESifo Working Paper series No. 517.

Conway, P. and G. Nicoletti (2006), "Product Market Regulation in the Non-Manufacturing Sectors of OECD Countries: Measurement and Highlights", OECD Economics Department Working Papers No. 530.

Conway, P., D. de Rosa, G. Nicoletti and F. Steiner (2006), "Product Market Regulation and Productivity Convergence", OECD Economic Studies No. 43: 39-76.

Crafts, N. (2006), "Regulation and Productivity Performance", Oxford Review of Economic Policy 22, No. 2, pp. 186-202.

Creusen, H., B. Minne, H. van der Wiel, (2006), "Measuring competition in the Netherlands, A comparison of indicators over the period 1993-2001", CPB Memorandum 163.

De Serres, A., S. Kobayakawa, T. Slok and L. Vartia (2006), "Regulation of Financial Systems and Economic Growth in OECD Countries: An Empirical Analysis", OECD Economic Studies No. 43: $77-113$.

Disney, R., J. Haskel and Y. Heden (2000), "Restructuring and Productivity Growth in UK Manufacturing”, CEPR Discussion Papers: 2463.

Faini, R., G. Barba Navaretti, J. Haskel, C. Scarpa and C. Wey (2006), "Contrasting Europe's Decline: Do Product Market Reforms Help?", in T. Boeri, M. Castanheira, R. Faini and V. Galasso (eds.) Structural Reforms Without Prejudices, Oxford University Press, Oxford. 
Forlani, E. (2010), "Competition in the Service Sector and the Performances of Manufacturing Firms: Does Liberalization Matter?", CESifo Working Paper series No. 2942.

Geroski, P. (1995a), "What do we know about entry?", International Journal of Industrial Organization, Vol. 13, pp. 421-440.

Geroski, P. (1995b), "Market Structure, Corporate Performance and Innovative Activity", Oxford, UK: Oxford University Press.

Greenhalgh, C. and M. Rogers (2006), "The value of innovation: The interaction of competition, R\&D and IP”, Research Policy, vol. 35(4), pp. 562-580.

Griffith, R. and R. Harrison (2004), "The Link Between Product Market Reform and MacroEconomic Performance", Economic Paper No. 209, European Commission.

Griffith, R., R. Harrison and H. Simpson (2006), "Product Market Reform and Innovation in the EU", CEPR Discussion Papers 5849.

Griffith, R., S. Redding and J. van Reenen (2004), "Mapping the Two Faces of R\&D: Productivity Growth in a Panel of OECD Countries", The Review of Economics and Statistics, Nov., 86(4): 883895.

Griffith, R., S. Redding and H. Simpson (2002), "Productivity Convergence and Foreign Ownership at the Establishment level", CEPR Discussion Paper No. 3765.

Grossman, G., and E. Helpman (1991), "Quality Ladders in the Theory of Growth", Review of Economic Studies 58, No. 1: 43-61.

Haskel, J., S. Pereira and M. Slaughter (2007), "Does Inward Foreign Direct Investment Boost the Productivity of Domestic Firms?", Review of Economics and Statistics 89, No. 3: 482-496.

Hendry, D.F. (1996), "Typologies of Linear Dynamic Systems and Models", Journal of Statistical Planning and Inference, 49, pp. 177-201.

Inklaar, R., M. Timmer and B. van Ark (2008), "Market Services Productivity across Europe and the US”, Economic Policy, Vol. 23, No. 53, pp. 139-194, January.

Lopez, J. (2010), Ph. D Dissertation, mimeo.

Melitz, M. (2003), “The Impact of Trade on Intra-Industry Reallocations and Aggregate Industry Productivity", Econometrica, vol. 71(6), pp. 1695-1725.

Melitz, M. and G. Ottaviano (2008), "Market Size, Trade, and Productivity", Review of Economic Studies 75, Issue 1.

Nickell, S. (1996), "Competition and Corporate Performance", Journal of Political Economy, 104, 724-746.

Nickell, S., D. Nicolitsas and N. Dryden (1997), "What Makes Firms Perform Well?", European Economic Review, 41.

Nicoletti, G. and F. Pryor (2006), "Subjective and Objective Measures of Governmental Regulations in OECD Nations", Journal of Economic Behaviour and Organization, 59, No.3, pp.433-449. 
Nicoletti, G. and S. Scarpetta (2003), "Regulation, Productivity and Growth", Economic Policy, Vol. 36, pp. 11-72.

Nicoletti, G. and S. Scarpetta (2006), "Regulation and Economic Performance: Product Market Reforms and Productivity in the OECD", in Institutions, Development, and Economic Growth (T. Eicher and C. Garcia-Peñalosa eds.), MIT Press.

Parente, S.L. and E.C. Prescott (1994), "Barriers to Technology Adoption and Development.", Journal of Political Economy 102, No. 2: 298-321.

Parente, S.L. and E.C. Prescott (1999), "Monopoly Rights: A Barrier to Riches.", American Economic Review 89, No. 5: 1216-1233.

Restuccia, D. and R. Rogerson (2007), "Policy Distortions and Aggregate Productivity with Heterogeneous Plants", National Bureau of Economic Research, NBER Working Papers: 13018.

Romer, P. (1990), "Endogenous Technological Change." Journal of Political Economy, 98, No. 5: S71-02.

Schiantarelli, F. (2005), "Product Market Regulation and Macroeconomic Performance: A Review of Cross Country Evidence”, IZA Discussion Papers ,1791.

Van Biesebroeck, J. (2004), "Cross-country Conversion Factors for Sectoral Productivity Comparisons", NBER Working Papers, 10279. 


\section{Appendix 1}

\section{The theoretical model}

This appendix - drawn from Lopez (2010) - summarizes the theoretical model presented in section 2 .

\section{Preferences and technology}

We consider an economy composed of a unit mass of identical consumers. Each consumer has an instantaneous utility function: $u()=.\int_{0}^{1} \ln \left(x_{j}\right) d j . x_{j}$ being consumption of final good from industry $j$. Because of the logarithmic utility function each industry receives the same expenditure share. Spending on each final good is normalised to unity, then the inverse demand function is: $p_{j}=1 / x_{j} \forall j$. Each final good is produced using an intermediate good as the only input, according to a production function linear on input: $x_{i j}=\gamma^{k i} . l_{i}, x_{i j}$ being the quantity of good $j$ produced by the firm $i$ using a quantity $l_{i}$ of intermediate input, $k_{i}$ the technological level of the firm $i$ and $\gamma$ captures the size of the efficiency improvement steps $(\gamma>1)$. Final good producers (henceforth called downstream firms) can move one technological step ahead at a Poisson hazard rate $\alpha$, by incurring a cost $f(\alpha)$, and we assume that this step is the largest gap that can separate the leader from followers due to knowledge externalities. Consequently three types of firms, indexed by $i \in\{-1,0,1\}$, exist: followers $(i=-1)$, leaders $(i=1)$, or firms in a leveled industry $(i=0)$.

\section{Market imperfections and price setting rules}

Firms compete in price. In an unleveled industry, a leader maximizes its profit $\pi_{1}$ by applying a limit pricing rule, setting a price that make the profit $\pi_{-1}$ of the follower equal to zero, thus grabbing all the expenditure share of its variety. In a leveled industry profits should be equal to zero, but we assume a degree of collusion $\epsilon<1$ between firms, thus the total profit for the industry is equal to $\varepsilon \pi_{1}$, and each firm earns $\boldsymbol{\pi}_{\mathbf{0}}=\boldsymbol{\epsilon} \cdot \boldsymbol{\pi}_{\mathbf{1}} / \boldsymbol{N}$. Thus, the leader's profit also determines the instantaneous profit flows for each type of firm. To calculate it we need to define the intermediate input prices and leader's optimal output price. Intermediate input suppliers (henceforth called upstream firms) are assumed to operate in an imperfectly competitive market. As a result, finding a supplier of intermediate input, which is a necessary requirement to start producing, involves a Poisson hazard rate of $\rho<1$. Such market imperfections translate into a certain degree $\beta$ of market power when upstream firms set input prices, which reflects the impossibility for downstream producers to instantaneously replace one supplier with another. Thus, the input price $\boldsymbol{p}_{\boldsymbol{i}}^{\boldsymbol{I I}}$ is fixed above the (constant) marginal cost c of producing intermediate inputs $1_{i}$. It is an outcome of a bargaining between upstream and downstream firms on the total rent $\mathrm{R}_{\mathrm{i}}$ :

$\left\{\begin{array}{c}\left(p_{i}^{I I}-c\right) \cdot l_{i}=\beta \cdot R_{i} \\ R_{i}=\pi_{i}+\left(p_{i}^{I I}-c\right) \cdot l_{i}\end{array} \Rightarrow p_{i}^{I I}=\frac{\beta}{1-\beta} \cdot \frac{\pi_{i}}{l_{i}}+c\right.$ 
The intermediate input price is increasing with the bargaining power of upstream firms, the unit profit of the downstream firm $\pi_{i} / l_{i}$, and the marginal cost of input production.

The downstream output price in an unleveled industry is determined by the price setting rule of the leader $(i=1)$ : it sets a price that makes the profit of the follower $(i=-1)$ equal to zero. Given consumer demand, the downstream firm production function and the input price setting formula, the downstream output price $p$ is: ${ }^{35}$

$\pi_{-1}=p \cdot x_{-1}-p_{-1}^{I I} \cdot l_{-1}=0 \Rightarrow p=\frac{c}{\gamma^{k-1}}$

The output price of a downstream firm, is increasing with the marginal cost of producing the intermediate input and decreasing with the technological level $k$ of the industry and the size $\gamma$ of the efficiency improvement steps.

Given the input and output prices the leader's profit is:

$\pi_{1}=(1-\beta) \cdot\left(p \cdot \gamma^{k}-c\right) \cdot l_{1} \Rightarrow \pi_{1}=(1-\beta) \cdot\left(1-\frac{1}{\gamma}\right)$

This profit is growing with the size of the efficiency improvement steps and decreasing with the power of negotiation of the upstream suppliers. It is worth noticing that it is independent of the input production marginal cost. Indeed, the power of negotiation of the upstream suppliers distorts competition between leaders and followers, making the input price depend on the profit of the firm, whereas the marginal cost of inputs is the same for all firms.

\section{Model solution and comparative statics}

The steady state Bellman equations associated to each possible state (leveled, leader, follower) can be expressed as:

$$
\begin{aligned}
& r J_{0}=\pi_{0}+\alpha \cdot\left(J_{1}-J_{0}\right)+\bar{\alpha} \cdot\left(J_{-1}-J_{0}\right)-\delta \cdot J_{0}-f(\alpha) \\
& r J_{1}=\pi_{1}+\lambda \cdot\left(J_{0}-J_{1}\right)-\delta \cdot J_{1} \\
& r J_{-1}=\pi_{-1}+(\lambda+\delta) \cdot\left(J_{0}-J_{-1}\right)-\delta \cdot J_{-1}
\end{aligned}
$$

with $r$ the discount rate, $\alpha$ the Poisson hazard rate of efficiency improvements, $\bar{\alpha}$ the hazard rate that another firm innovate, $\delta$ the exogenous rate of firm destruction, $f(\alpha)$ the cost of efficiency improvements and $\lambda$ the rate of catch-up ${ }^{36}$.

35 In order to simplify the presentation, industry indices for some variables are dropped from now on.

36 In Aghion et al. (2005) only two firms compete on each market and the catch-up probability depends on the follower's effort. In our model the number of downstream firms is endogenous but, in order to keep things tractable, the catch-up probability is exogenous. 
The downstream firms in a leveled industry choose the rate of efficiency improvements, or equivalently the level of spending needed for expecting such improvements, in order to maximize their value. From equation (2) the first order condition of the producer maximization program implies:

$\left.\frac{\partial J_{0}}{\partial \alpha}\right|_{N, \bar{\alpha}}=0 \Leftrightarrow \frac{\partial f\left(\alpha^{*}\right)}{\partial \alpha}=J_{1}\left(\alpha^{*}\right)-J_{0}\left(\alpha^{*}\right)$

In words, at the downstream firm optimum the marginal cost of efficiency improvements equals the expected gains from innovating. The second order condition is satisfied given our assumption on the shape of the cost function:

$\left.\frac{\partial^{2} J_{0}^{*}}{\partial \alpha^{2}}\right|_{N, \bar{\alpha}}=-\frac{\partial^{2} f\left(\alpha^{*}\right)}{\partial \alpha^{2}}<0$

The optimal rate of efficiency improvements can be derived as follows. From equations (2) and (4) we get:

$(r+\delta) \cdot J_{0}=(1-\Omega) \cdot\left(\pi_{0}+\alpha \cdot\left(J_{1}-J_{0}\right)-f(\alpha)\right)$

with $\Omega(\alpha) \equiv \frac{\bar{\alpha}}{r+2 \delta+\lambda+\bar{\alpha}}$ representing the risk to be overtaken by another innovator.

Then, from equations (3) and (6), the expected gains from efficiency improvements are:

$$
J_{1}-J_{0}=\frac{\pi_{1}-(1-\Omega) \cdot\left(\pi_{0}-f(\alpha)\right)}{r+\delta+\lambda+\alpha \cdot(1-\Omega)}
$$

Therefore, incentives for efficiency improvements are growing with the leader's profit and the level of competition downstream, as the profit in a leveled industry is decreasing with competition. The incentives are also increasing with the risk to be overtaken in a leveled industry.

Finally, from equations (5) and (7), the optimal rate of efficiency improvements is defined by the following equality:

$\frac{\partial f\left(\alpha^{*}\right)}{\partial \alpha}=\frac{\pi_{1}-\left(1-\Omega^{*}\right) \cdot\left(\pi_{0}-f\left(\alpha^{*}\right)\right)}{r+\delta+\lambda+\alpha^{*} .\left(1-\Omega^{*}\right)}$

\section{Short run}

To solve the model it is worth noticing that, from equations (3) and (5), the optimal rate of efficiency improvements, for a given number of firms, can be determined by the function:

$\Phi\left(\alpha^{*}, N\right) \equiv \frac{\pi_{1}-(r+\delta) \cdot J_{0}^{*}}{r+\delta+\lambda}-\frac{\partial f\left(\alpha^{*}\right)}{\partial \alpha}=0$ 
with the value of a firm in a leveled industry stemming from equations (6) and (7):

$(r+\delta) \cdot J_{0}=(1-\Omega) \cdot \frac{\alpha \cdot \pi_{1}+(r+\delta+\lambda) \cdot\left(\pi_{0}-f(\alpha)\right)}{r+\delta+\lambda+\alpha \cdot(1-\Omega)}$

We can use equation (8) to study the existence and uniqueness of the equilibrium efficiency improvements rate, for any given number of downstream firms. To this end we first find conditions for monotony of the $\Phi\left(\alpha^{*}, N\right)$ function:

$$
\begin{aligned}
& \left.\frac{\partial \Phi\left(\alpha^{*}, N\right)}{\partial \alpha}\right|_{N}=-\left(\left.\frac{r+\delta}{r+\delta+\lambda} \cdot \frac{\partial J_{0}^{*}}{\partial \alpha}\right|_{N}+\frac{\partial^{2} f\left(\alpha^{*}\right)}{\partial \alpha^{2}}\right) \\
& \left.\Rightarrow \frac{\partial \Phi\left(\alpha^{*}, N\right)}{\partial \alpha}\right|_{N}=\frac{r+\delta}{r+2 \delta+\lambda} \cdot(N-1) \cdot \frac{(1-\Omega) \cdot J_{0}^{*}}{r+\delta+\lambda+\alpha^{*} \cdot(1-\Omega)}-\frac{\partial^{2} f\left(\alpha^{*}\right)}{\partial \alpha^{2}}
\end{aligned}
$$

The sign of this derivative is not straightforward. The marginal cost of improvements is increasing with the rate of improvements, but the expected gains from improvements are also increasing. Indeed, through the risk to be overtaken $\Omega$, the rate of efficiency improvements has a negative externality effect on the value of a firm in a leveled industry. If the expected gains from improvements increase more than its marginal costs the equation $\Phi(\alpha, N)$ is growing with the rate of efficiency improvements and the equilibrium rate could be infinite. In the following, we assume that the acceleration in the cost of efficiency improvements $\frac{\partial^{2} f\left(\alpha^{*}\right)}{\partial \alpha^{2}}$ is stronger than the externality effect. Under this condition the function $\Phi(\alpha, N)$ is strictly decreasing with the rate of efficiency improvements.

Second, we study the limits of the $\Phi\left(\alpha^{*}, N\right)$ function:

$$
\begin{aligned}
& \left\{\begin{array}{c}
\lim _{\alpha \rightarrow 0} \Phi(\alpha, N)=\frac{\pi_{1}-\left(\pi_{0}-\lim _{\alpha \rightarrow 0} \mathrm{f}(\alpha)\right)}{\mathrm{r}+\delta+\lambda}-\lim _{\alpha \rightarrow 0} \frac{\partial \mathrm{f}(\alpha)}{\partial \alpha} \Rightarrow \lim _{\alpha \rightarrow 0} \Phi(\alpha, N)>0 \\
\lim _{\alpha \rightarrow 0} \mathrm{f}(\alpha)=0 \text { and } \lim _{\alpha \rightarrow 0} \frac{\partial \mathrm{f}(\alpha)}{\partial \alpha}=0 \text { by assumption }
\end{array}\right. \\
& \left\{\begin{array}{c}
\lim _{\alpha \rightarrow+\infty} \Phi(\alpha, N)=\frac{\pi_{1}}{\mathrm{r}+\delta+\lambda} \cdot\left(1-\frac{1}{\chi}\right)+\frac{1}{\chi} \cdot \lim _{\alpha \rightarrow+\infty}\left[\frac{\mathrm{f}(\alpha)}{\alpha} \cdot\left(1-\chi \cdot \frac{\alpha \cdot \partial \mathrm{f}(\alpha) / \partial \alpha}{\mathrm{f}(\alpha)}\right)\right] \\
\quad \chi \equiv 1+(\mathrm{N}-1) \cdot \frac{\mathrm{r}+\delta+\lambda}{\mathrm{r}+2 \delta+\lambda} \\
\lim _{\alpha \rightarrow+\infty} \frac{\mathrm{f}(\alpha)}{\alpha}=+\infty \text { and } \lim _{\alpha \rightarrow+\infty} \frac{\alpha \cdot \partial \mathrm{f}(\alpha) / \partial \alpha}{\mathrm{f}(\alpha)}>1 \text { by assumption }
\end{array}\right. \\
& \Rightarrow \lim _{\alpha \rightarrow+\infty} \Phi(\alpha, N)<0
\end{aligned}
$$


Therefore, for any given number of downstream producers, under some assumptions on the cost function of efficiency improvements, the function $\Phi(\alpha, N)$ is strictly decreasing with the rate of efficiency improvements and defines a unique finite equilibrium efficiency improvements rate.

We then turn to the comparative statics of the model for a given number of downstream producers.

a. The effect of the rate of efficiency improvements on the value of a firm in a leveled industry is:

$\left.\frac{\partial J_{0}}{\partial \alpha}\right|_{N}=\left.\left.\frac{\partial J_{0}}{\partial \Omega}\right|_{N, \alpha} \cdot \frac{\partial \Omega}{\partial \alpha}\right|_{N}+\left.\frac{\partial J_{0}}{\partial \alpha}\right|_{N, \Omega}$

At the producer optimum the private effect of an increase in the rate of efficiency improvements is equal to zero, but there is an externality effect due to the impact of the rate of efficiency improvements on the risk to be overtaken by other innovators $(\Omega)$ :

$$
\begin{aligned}
& \left\{\begin{array}{c}
\left.\frac{\partial J_{0}}{\partial \Omega}\right|_{N, \alpha}=-\frac{r+\delta+\lambda}{1-\Omega} \cdot \frac{J_{0}}{r+\delta+\lambda+\alpha \cdot(1-\Omega)} \\
\left.\frac{\partial \Omega}{\partial \alpha}\right|_{N}=(N-1) \cdot \frac{r+\delta+\lambda}{(r+\delta+\lambda+\bar{\alpha})^{2}} \\
\left.\quad \frac{\partial J_{0}}{\partial \alpha}\right|_{N, \Omega}=0
\end{array}\right. \\
& \left.\Rightarrow \frac{\partial J_{0}}{\partial \alpha}\right|_{N}=-(N-1) \cdot \frac{r+\delta+\lambda}{r+2 \delta+\lambda} \frac{(1-\Omega) \cdot J_{0}}{r+\delta+\lambda+\alpha \cdot(1-\Omega)}<0
\end{aligned}
$$

- The value of a firm in a leveled industry decreases with the rate of efficiency improvements, for a given number of downstream producers, because of the corresponding increase in the risk to be overtaken.

b. The effect of the bargaining power of upstream firms on the value of a firm in a leveled industry, for a given number of firms and rate of efficiency improvements is:

$$
\begin{aligned}
& \left.\frac{\partial J_{0}^{*}}{\partial \beta}\right|_{\alpha, N}=\left.\left.\frac{\partial J_{0}^{*}}{\partial \pi_{1}}\right|_{\alpha, N} \cdot \frac{\partial \pi_{1}}{\partial \beta}\right|_{\alpha, N} \\
& \left\{\begin{array}{c}
\left.\frac{\partial J_{0}^{*}}{\partial \pi_{1}}\right|_{\alpha, N}=\frac{1-\Omega^{*}}{r+\delta} \cdot \frac{\alpha^{*}+(r+\delta+\lambda) \cdot \epsilon / N}{r+\delta+\lambda+\alpha^{*} \cdot\left(1-\Omega^{*}\right)}>0 \\
\left.\quad \frac{\partial \pi_{1}}{\partial \beta}\right|_{\alpha, N}=-\frac{\pi_{1}}{1-\beta}<0
\end{array}\right. \\
& \left.\Rightarrow \frac{\partial J_{0}^{*}}{\partial \beta}\right|_{\alpha, N}=-\frac{\pi_{1}}{1-\beta} \cdot \frac{1-\Omega^{*}}{r+\delta} \cdot \frac{\alpha^{*}+(r+\delta+\lambda) \cdot \epsilon / N}{r+\delta+\lambda+\alpha^{*} \cdot\left(1-\Omega^{*}\right)}<0
\end{aligned}
$$


- As the bargaining power of upstream firms has a negative effect on the profits of downstream firms, it also has a negative impact on the value of a firm in a leveled industry.

c. Finally, the effect of the bargaining power of upstream producers on the optimal efficiency improvements rate is:

$$
\begin{aligned}
& \left.\frac{\partial \Phi\left(\alpha^{*}, N\right)}{\partial \beta}\right|_{\alpha, N}=\frac{\partial \pi_{1} / \partial \beta-\left.(r+\delta) \cdot \frac{\partial J_{0}}{\partial \beta}\right|_{\alpha, N}}{r+\delta+\lambda}<0 \\
& \left.\Rightarrow \quad \frac{\partial \alpha}{\partial \beta}\right|_{N}=-\frac{\left.\frac{\partial \Phi\left(\alpha^{*}, N\right)}{\partial \beta}\right|_{\alpha, N}}{\left.\frac{\partial \Phi\left(\alpha^{*}, N\right)}{\partial \alpha}\right|_{N}}<0
\end{aligned}
$$

- For a given number of downstream producers, the optimal rate of efficiency improvements is decreasing with the power of negotiation of the upstream firms.

\section{Long run}

The endogenous number of downstream producers is defined by the following condition:

$r V=\rho . J_{0}-b=0 \Leftrightarrow J_{0}=b / \rho$

with $V$ the value of a firm searching for a supplier of intermediate inputs, $\rho$ the Poisson hazard rate to find one and $b$ the searching cost.

As the search for an intermediate input supplier is time consuming it reduces access to the downstream market. The equilibrium number of downstream producers and rate of efficiency improvements are given by the system composed by equations (12), (8) and (9). The long-run rate of efficiency improvements solution to this system is:

$\frac{\partial f\left(\alpha^{*}\right)}{\partial \alpha}=\frac{\pi_{1}-(r+\delta) \cdot b / \rho}{r+\delta+\lambda}$

- The rate of optimal efficiency improvements is growing with the hazard rate to find an intermediate input supplier and declining with the search cost.

- The bargaining power of upstream firms has a negative effect of the equilibrium optimal rate of efficiency improvements.

The following points $\mathrm{a}, \mathrm{b}, \mathrm{c}$ and $\mathrm{d}$ describe how short and long run properties of the model interact to lead to this reduced equation and to the corresponding implications. 
a. The effect of the number of downstream producers on the value of a firm in a leveled industry, for a given rate of efficiency improvements is:

$\left.\frac{\partial J_{0}}{\partial N}\right|_{\alpha}=\left.\left.\frac{\partial J_{0}}{\partial \Omega}\right|_{N, \alpha} \cdot \frac{\partial \Omega}{\partial N}\right|_{\alpha}+\left.\frac{\partial J_{0}}{\partial N}\right|_{\alpha, \Omega}$

$$
\begin{aligned}
& \left\{\begin{array}{c}
\left.\frac{\partial J_{0}}{\partial \Omega}\right|_{N, \alpha}=-\frac{r+\delta+\lambda}{r+\delta+\lambda+\alpha \cdot(1-\Omega)} \cdot \frac{J_{0}}{1-\Omega}<0 \\
\left.\frac{\partial \Omega}{\partial N}\right|_{\alpha}=\Omega \cdot \frac{(1-\Omega)}{N-1}>0 \\
\left.\frac{\partial J_{0}}{\partial N}\right|_{\alpha, \Omega}=-\frac{1-\Omega}{r+\delta} \cdot \frac{r+\delta+\lambda}{r+\delta+\lambda+\alpha \cdot(1-\Omega)} \cdot \pi_{0}<0
\end{array}\right. \\
& \left.\Rightarrow \frac{\partial J_{0}}{\partial N}\right|_{\alpha}=-\frac{r+\delta+\lambda}{r+\delta+\lambda+\alpha \cdot(1-\Omega)} \cdot\left(\Omega \cdot \frac{J_{0}}{N-1}+\frac{1-\Omega}{r+\delta} \cdot \frac{\pi_{0}}{N}\right)<0
\end{aligned}
$$

- Increasing the number of downstream producers has two negative effects on the value of a firm in a leveled industry: it decreases the profit of these firms and increases the risk to be overtaken.

b. The effect of the number of downstream producers on the rate of optimal efficiency improvements is:

$$
\begin{aligned}
& \left.\frac{\partial \Phi\left(\alpha^{*}, N\right)}{\partial N}\right|_{\alpha}=-\left.\frac{r+\delta}{r+\delta+\lambda} \cdot \frac{\partial J_{0}}{\partial \mathrm{N}}\right|_{\alpha}>0 \\
& \Rightarrow \quad \frac{\partial \alpha}{\partial N}=-\frac{\left.\frac{\partial \Phi\left(\alpha^{*}, N\right)}{\partial N}\right|_{\alpha}}{\left.\frac{\partial \Phi\left(\alpha^{*}, N\right)}{\partial \alpha}\right|_{N}}>0
\end{aligned}
$$

- Increasing the number of downstream producers has two positive effects on the optimal efficiency improvements rate. First, the profit of a firm in a leveled sector decreases, because it has to share the rent with more downstream producers. Second, the risk of being overtaken also increases.

c. The effects of the hazard rate of finding an intermediate input supplier and of the corresponding search cost on the optimal rate of efficiency improvements can be inferred as follows. We know that the value of a firm in a leveled industry decreases with the number of competitors:

$\frac{\partial J_{0}}{\partial N}=\left.\frac{\partial J_{0}}{\partial \alpha}\right|_{N} \cdot \frac{\partial \alpha}{\partial N}+\left.\frac{\partial J_{0}}{\partial N}\right|_{\alpha} \Rightarrow \frac{\partial J_{0}}{\partial N}<0$

But, from the free entry condition (12), we also know that the number of firms decreases with the searching cost $b$ and increases with the hazard rate $\rho$ to find a supplier of intermediate input. Moreover, the rate of optimal efficiency improvements is increasing with the number of downstream producers. 
- Therefore, the rate of optimal efficiency improvements is growing with the hazard rate to find an intermediate input supplier and declining with the search cost.

d. The effect of the bargaining power of upstream firms on the optimal rate of efficiency improvements is:

$$
\begin{aligned}
& \left\{\begin{array}{c}
\frac{\partial \alpha}{\partial \beta}=\frac{\partial \alpha}{\partial N} \cdot \frac{\partial N}{\partial \beta}+\left.\frac{\partial \alpha}{\partial \beta}\right|_{N} \\
\frac{\partial N}{\partial \beta}=-\frac{\left.\frac{\partial J_{0}}{\partial \beta}\right|_{N}}{\frac{\partial J_{0}}{\partial N}}=-\frac{\left.\left.\frac{\partial J_{0}}{\partial \alpha}\right|_{N} \cdot \frac{\partial \alpha}{\partial \beta}\right|_{N}+\left.\frac{\partial J_{0}}{\partial \beta}\right|_{\alpha, N}}{\left.\frac{\partial J_{0}}{\partial \alpha}\right|_{N} \cdot \frac{\partial \alpha}{\partial N}+\left.\frac{\partial J_{0}}{\partial N}\right|_{\alpha}}
\end{array}\right. \\
& \Rightarrow \frac{\partial \alpha}{\partial \beta}=\left(\frac{\partial J_{0}}{\partial N}\right)^{-1} \cdot\left(\left.\left.\frac{\partial J_{0}}{\partial N}\right|_{\alpha} \cdot \frac{\partial \alpha}{\partial \beta}\right|_{N}-\left.\frac{\partial J_{0}}{\partial \beta}\right|_{\alpha, N} \cdot \frac{\partial \alpha}{\partial N}\right)<0
\end{aligned}
$$

The impact of the bargaining power of upstream firms on the optimal efficiency improvements rate works through the effect on the number of downstream producers. This effect is negative only under certain conditions, ${ }^{37}$ but these conditions are not necessary for signing the effects of bargaining power on the rate of efficiency improvements.

- The bargaining power of upstream firms has a negative effect of the equilibrium optimal rate of efficiency improvements.

37 The bargaining power of upstream firms has contrasting effects on the number of downstream firms:

$\left.\frac{\partial J_{0}}{\partial \beta}\right|_{N}=\left.\left.\frac{\partial J_{0}}{\partial \alpha}\right|_{N} \cdot \frac{\partial \alpha}{\partial \beta}\right|_{N}+\left.\frac{\partial J_{0}}{\partial \beta}\right|_{N, \alpha}$

As we have already seen, $\left.\frac{\partial J_{0}}{\partial \beta}\right|_{N, \alpha}<0,\left.\frac{\partial J_{0}}{\partial \alpha}\right|_{N}<0$ and $\left.\frac{\partial \alpha}{\partial \beta}\right|_{N}<0$, then, for a given number of firms, the bargaining power of upstream firms has two contrasting effects on the value of a firm in a leveled industry: for a given rate of efficiency improvements it decreases the value of a firm, but it decreases also the rate of efficiency improvements thereby increasing the value of a firm.

We can show that the negative impact overcomes the positive effect if, and only if:

$\frac{\partial^{2} f\left(\alpha^{*}\right)}{\partial \alpha^{2}}>\frac{\rho}{b} \cdot \frac{r+\delta}{r+2 \delta+\lambda} \frac{N-1}{(r+\delta+\lambda) \cdot \frac{\epsilon}{N}+\alpha}$

This condition is stronger than the one needed to have a unique finite equilibrium. However this condition isn't necessary to determine the impact of the bargaining power of upstream firms on the optimal efficiency improvements rate. 


\section{Appendix 2}

\section{Data description}

\section{Product market indicators}

\section{a. The OECD indicators of non-manufacturing regulation}

The overarching criterion on which this paper surveys and assesses regulations is their effect on competition where competition is viable. Each of the OECD sectoral indicators reflects regulations that curb efficiency-enhancing competition, whereas regulations in areas in which competition would not lead to efficient outcomes (e.g. natural monopolies) are not considered. This approach yields indicators that are well-focused and account for the different technological characteristics of sectors. At the same time, the indicators are silent on the quality of regulation according to criteria other than competition or the extent to which regulations achieve non-economic policy goals.

By and large, all the indicators are constructed in a similar way. They cover information in four main areas: state control, barriers to entry, involvement in business operations and, in some cases, market structure. The information summarised by the indicators is "objective", as opposed to survey-based, and consists of rules, regulations and market conditions. All of these regulatory data are vetted by OECD Member country officials and/or OECD experts. The indicators are calculated using a bottom-up approach in which the regulatory data are quantified using an appropriate scoring algorithm and then aggregated into summary indicators by sector of activity in each of the four areas or across them. While this approach involves a degree of discretion, notably in choosing scores and aggregation weights, it has the merit of transparency and makes it possible to trace each indicator value to the underlying detailed information about policies and market conditions.

The resulting indicators of non-manufacturing regulation cover energy (gas and electricity), transport (rail, road and air) and communication (post, fixed and cellular telecommunications) over the 1975-2007 period, and retail distribution and professional services for 1998 and 2003 in 30 OECD countries. These indicators are used to derive 'regulatory burden' indicators of the trickle down effects of anti-competitive regulation in these sectors (plus the finance sector) on sectors that use the outputs of these sectors as intermediate inputs. All indicators are updated on a regular basis and their values as well as background documentation are publicly available at www.oecd.org/eco/pmr (see Conway and Nicoletti, 2006).

\section{b. Measuring the effects of anti-competitive non-manufacturing regulation on downstream industries: the 'regulatory burden' indicators}

The trickle down effects of non-manufacturing regulation are likely to have become particularly salient over recent years given the large and increasingly important role of the nonmanufacturing sector as a supplier of intermediate inputs in OECD countries. For example, on average across countries for which (harmonised) input-output data exist, in the late 1990s almost 80\% of the output of the business services sector was used as an intermediate input in the production processes of other sectors in the economy. Similarly, between 50 and $70 \%$ of the output of the finance, electricity, and post and telecoms sectors is destined to be used as intermediate inputs to the 
production process. In addition, the importance of non-manufacturing sectors as a source of intermediate inputs has been growing rapidly over recent decades, along with the rest of the services sector. For example, Kongsrud and Wanner (2005) report that the service sector now accounts for roughly $70 \%$ of all jobs and value-added in the OECD area, which is more than 5 percentage points higher than in 1990.

In any given country the magnitude of the effects of non-manufacturing regulation on the economy will be a reflection of two factors:

- the extent of anti-competitive regulation in non-manufacturing sectors, and

- the importance of these sectors as suppliers of intermediate inputs.

The first of these factors is captured by the OECD indicators of regulation in non-manufacturing sectors; ${ }^{38}$ the second factor is measured using total input coefficients derived from (harmonised) input-output tables, which provide a snapshot view of the purchases and sales of intermediate inputs between different sectors in a given year. ${ }^{39}$

Using total input-output coefficients, the regulatory burden indicators (REG) are calculated as follows in each country: ${ }^{40}$

$$
R E G_{k t}=\sum_{j} N M R_{j t} \bullet w_{j k} \quad 0<w_{j k}<1
$$

where the variable $N M R_{j t}$ is an indicator of anti-competitive regulation in non-manufacturing sector $j$ at time $t$ and the weight $w_{j k}$ is the total input requirement of sector $k$ for intermediate inputs from nonmanufacturing sector $j$. The (harmonised) input-output data for OECD countries, and therefore the $w_{j k}$, exist at the 2-digit (ISIC rev3) level, implying that the NMR must also be calculated at this level of sectoral aggregation. Accordingly, the NMR indicators are mapped into the ISIC system as shown in figure A2.1. If more than one of the NMR indicators map into a given 2-digit ISIC sector then $N M R_{j t}$ is calculated as a simple average of the constituent indicators. Finally REG is normalized on $[0 ; 1]$ over the study sample

Where $k=j$ in the above formula, $w_{j j}$ is the total input requirement for the sector's own output. In this paper, we focus on the indirect effect of regulation in upstream sectors on sectors downstream. Therefore, the 'regulatory burden' indicators used in empirical analysis are constructed

38 As mentioned above, an indicator of anti-competitive regulation in the finance sector - described in detail in de Serres $e t$ al. (2006) - is also used as part of the analysis of anti-competitive regulation in non-manufacturing and the calculation of the regulatory burden indicators.

39 Total input coefficients are calculated as follows. If $\mathrm{Y}$ is a vector of industry gross outputs, D a vector of demand for final goods, and A a matrix of technical coefficients - that is, the share of inputs from industry $\mathrm{j}$ used in producing one unit of output of industry $\mathrm{k}$ - then the basic relation between output and final demand can be expressed as:

$\mathrm{D}=(\mathrm{I}-\mathrm{A}) \mathrm{Y}$, or alternatively, $\mathrm{Y}=(\mathrm{I}-\mathrm{A})^{-1} \mathrm{D}$

In this equation $(\mathrm{I}-\mathrm{A})^{-1}$ is the Inverse Leontief Matrix of the input-output coefficients and describes how many units of an industry's output have to be produced at any stage of the value chain in order to produce one unit for final demand.

40 This technique for calculating the regulatory burden indicators is a variant of that used by Faini et al. (2006). Total inputoutput coefficients have also been used by Allegra et al. (2004) to derive the impact on export-oriented sectors of economic activities that are problematic from the point of view of antitrust law. 
under the constraint $w_{j j}=0$ for any $j$. In other words, we ignore both the impact of regulation in sector $j$ originating from consumption of intermediate inputs produced by the same sector and the direct impact of the sector's regulation on productivity outcomes.

The 'regulatory burden' indicators are calculated in this way for 20 (ISIC rev3) sectors in the 15 OECD countries covered by our sample over the period 1984 to 2007. It should be noted that, in the formula, $N M R_{j t}$ is equal to either the indicators for energy, transport and communication industries, for which complete time-series data are available, or the indicators for the other sectors (retail trade, professional services and finance), which have been estimated for only 2003 (finance) or 1998, 2003 and 2007 (retail trade and professional services). For the purpose of computing the 'regulatory burden' indicators, regulation for retail and professional services was kept constant at its 1998 value. Given the limited time variability of regulation in these sectors (Figure 1), this is a relatively weak assumption. In any case, it is important to keep in mind that, due to data limitations, the variability of the 'regulatory burden' indicators in the time dimension reflects changes in the regulation of the energy, transport and communication sectors.

\section{Productivity}

MFP measures and distance to frontier indices are derived from data on value added, total employment and net capital stock contained in OECD industry databases. Net capital stocks in the Productivity database by industry (PDBi) are computed with the Permanent Inventory Method (PIM) on a single asset, assuming geometric rates of depreciation and investment taking place in mid-period. PDBi made available net capital stock series using four different assumptions to compute the initial capital stock. In this study the initial capital stock is estimated for the year 1984 by the cumulative depreciated past investment, using the long-run growth rate of investment volume. ${ }^{41}$

As discussed in the text the panel is cleaned. Observations with TFP growth over $+1-50 \%$ are excluded from the sample (48 observations) as well as observations with MFP more than 20 times smaller than the MFP of the leading country (18 observations). Mistaken changes in the variables gap and 'leader MFP growth' occur when the leading country enter or exit of the sample because of data availability. In order to take into account of this issue, all observations before the entrance or after the exit of the leading country are excluded from the sample, when the concerned years are few (64 observations). When, on the contrary, the data availability of this leading country is scarce, the variables gap and 'leader MFP growth' are calculated using MFP of the first follower, assuming that this second country is a good approximation of the first, and the leading country is excluded from the sample (73 observations).

Finally a cleaned unbalanced panel of 4629 observations from 15 countries and 20 industries on 1984-2005 is available for the estimations. The 15 countries are: Australia, Austria, Belgium, Canada, Denmark, Finland, France, Germany, Greece, Italy, Netherlands, Norway, Spain, Sweden and United-States. See figure A2.2 for the industry list.

41 A full presentation of the data and methods used to calculate the net capital stocks is available in the "PDBi Methodological Notes". 


\section{Appendix 3}

\section{Analysis of robustness and significance}

The robustness of the estimations has been tested on several counts: the estimation period; the country coverage; the sector coverage; the input-output matrix used to calculate the regulatory burden indicators; the price measurement of the output of 'electrical and optical equipment' (30-33); the type of PPP adjustment; and the measurement of MFP. We have also estimated the same model using labour productivity (LP) as a dependent variable. This appendix focuses on the 1995-2007 period. The conclusions of the sensitivity analysis are broadly the same over the whole period (19852007).

\section{Estimation period}

The estimation of equation (7) has been carried out on a moving 15-year time window (see Table A3-1). The increasing impact (in absolute terms) of regulations and the decreasing impact of the gap show up progressively over time. In parallel, the impact of the interaction term decreases progressively. These developments are most apparent when the last years of the 1980s are excluded and the first years of the 2000s are included in the dataset. This observation gives some support to the idea discussed above that the change in results over time is due to increased integration of the world economy in the context of the diffusion of new technologies.

\section{Country coverage}

The estimation of equation (7) has been carried out by dropping one country at a time in order to check that estimation results are not driven by the inclusion of any particular country (see Table A3-2). The results are quite robust to these changes in coverage, which affect neither the sign of the coefficients nor their significance. More precisely, we observe that: (i) the MFP frontier growth and the gap coefficients experience only marginal changes; (ii) the coefficient of REG and the interaction term between REG and gap are within a one standard-deviation interval except in two cases, Austria for REG and Greece for the interaction term, for which the coefficient is higher. Our main results could therefore be seen as lower bound estimates.

\section{Sector coverage}

The estimation of equation (7) has been carried out by dropping one sector at a time in order to check that estimation results are not driven by the inclusion of any particular sector (see Table A3$3)$. The results are again quite robust. Changes in sector coverage affect neither the sign of the coefficients nor their significance. More precisely, we observe that: (i) The MFP frontier growth coefficient decreases by more than $20 \%$ only when the sector 'electrical and optical equipment' (3033) is dropped; (ii) The gap coefficient experiences only marginal changes; (iii) the coefficients of REG and of the interaction term between REG and gap sometimes change by more than $20 \%$ but remain always within a one standard-deviation interval. 


\section{Input-output matrices used to calculate the regulatory burden indicators}

Choice of the US input-output matrix in the baseline estimations was motivated by the wish to minimize: (i) measurement error biases, supposing that the US matrix is estimated more precisely than in other countries; (ii) endogeneity biases, the technical coefficients of national input-output matrices being potentially influenced by the degree of regulation. Ideally, one would want to use the input-output table from a country not included in the estimation sample and without any anticompetitive regulation in non manufacturing sectors. While strictly speaking such a country does not exist, the United-Kingdom is a second best choice as its regulations are close to best practice in many sectors. We therefore re-estimated our specification with the 'regulatory burden' indicators calculated using the UK input-output table. We also extended the robustness check to estimations using country-specific input-output tables. Finally, we estimated our baseline equation (with the US table) but excluding US observations. The results are remarkably robust to these changes (see Table A3-4). The coefficients experience only marginal changes when the domestic input-output matrices are used. The coefficients change more, especially the one of REG and, to a lesser extent, the one of the interaction term between REG and gap, when the UK input-output matrix is used. But the changes never affect the sign of the coefficients and affect only slightly the estimation precision.

\section{Price measurement of the output of 'electrical and optical equipment' (30-33)}

In the baseline estimation, the output price index used for the US 'electrical and optical equipment' (30-33) sector is the global manufacturing output price. This choice has been made because hedonic methods for building the output price index for this sector are more common in the US than in other countries, which could have important implications for the estimates given the larger correction for improved quality in only one country. We observe that the results change marginally if the US are excluded from the dataset or if the US relative price of the sector "electrical and optical equipment' (30-33) is used as the output price index for all countries (see Table A3-5). However, if the US index price of the 'electrical and optical equipment' (30-33) sector is used only for the US MFP calculation, we observe some impact: the coefficient of the interaction term between REG and gap decreases (in absolute terms).

\section{PPP adjustment}

In the baseline estimation, the PPP adjustment is realized for each country with a national level PPP index (provided by the OECD) for the volume MFP level calculation. An alternative choice is to use sector-specific PPPs. In principle this choice would be more appropriate but, in practice sector-specific indices suffer from more serious measurement error, with the consequent estimation bias risks. We have tried this alternative, using the Inklaar and Timmer (2008) method for constructing sector-specific PPP indices for each country as follows:

$$
\ln \left(P P P_{-} P_{c s}\right)=\bar{\omega}_{c s} \cdot \ln \left(P P P_{-} V A_{c s}\right)+\left(1-\bar{\omega}_{c s}\right) \cdot \ln \left(P P P_{-} I I_{c s}\right)
$$

where PPP_P are the PPPs on gross ouput from the EUKLEMS industry database, $\bar{\omega}_{c s} \equiv\left(\omega c s+\omega_{U S S}\right) / 2$ with $\omega_{c s}$ the ratio of value added to gross output in current price, from the 
STAN database, $P P P_{-} V A$ the PPPs for value added and PPP_II the PPPs for intermediate inputs, computed using input-output tables and PPPs for inputs from OECD input-output databases.

Compared to the baseline estimation, the average impact of the regulatory burden indicator does not change sensibly, but the coefficient estimates of the gap and of its interaction with the regulatory burden indicator decrease.(see Table A3-6). As this may reflect more measurement bias than in the baseline estimation, we have decided to report results using the national level PPP indices.

\section{MFP measurement}

Due to decreasing returns at the extensive and intensive margins of labour utilisation, the elasticities of productivity to working time and to the employment rate are negative (see Bourlès and Cette, 2005, 2007). In each country*sector, MFP growth may partly capture changes in the working time and in the employment rate, and the distance of the MFP level to the frontier (gap) may also be partly reflect differences in these factors. To account for this possibility, we used the elasticity estimates of Aghion et al. (2009) ${ }^{42}$ and the gaps with the US in working time and employment rates to calculate for each country*sector*year, a "structural" MFP level, defined as the one that would be observed if, at any moment, the working time and the employment rate were the same as in the US. We then estimated equation (3) using these "structural" MFP measures instead of our baseline MFP variable. Compared to the baseline estimation, the coefficient estimates decrease (in absolute terms), except for the coefficient of REG (see Table A3-6). As this may reflect more measurement bias we decided to report results using the standard MFP measures.

To calculate MFP, different assumptions can also be made concerning the labour share in value added. In the baseline estimation, this share is sector-specific, and is calculated for each sector by taking the average of the labour share over all countries and years in the dataset. Estimation of equation (3) has also been made using four other measures of the labour share. These four alternative measures are described in Table A3-7. Results are quite robust to using these different measures.

\section{Productivity measurement: Labour productivity (LP) or MFP}

Equation (7) has also been estimated using labour productivity (LP) instead of MFP as a measure of productivity. The various specifications tested are shown in Table A3-8. From a qualitative point of view, when all available observations are used results are very similar to our baseline MFP estimates (compare columns 1 and 6). However, the precision of the coefficient estimates of the gap and its interaction with the regulatory burden indicator decreases.

42 These elasticities come from the estimates of Aghion et al. (2009). 
Figure 1. Non manufacturing regulation trends and cross-country dispersion (scale 0-6 from least to most restrictive of competition)

A. Regulation in energy, transport and communication ${ }^{1}, 1975-2007$

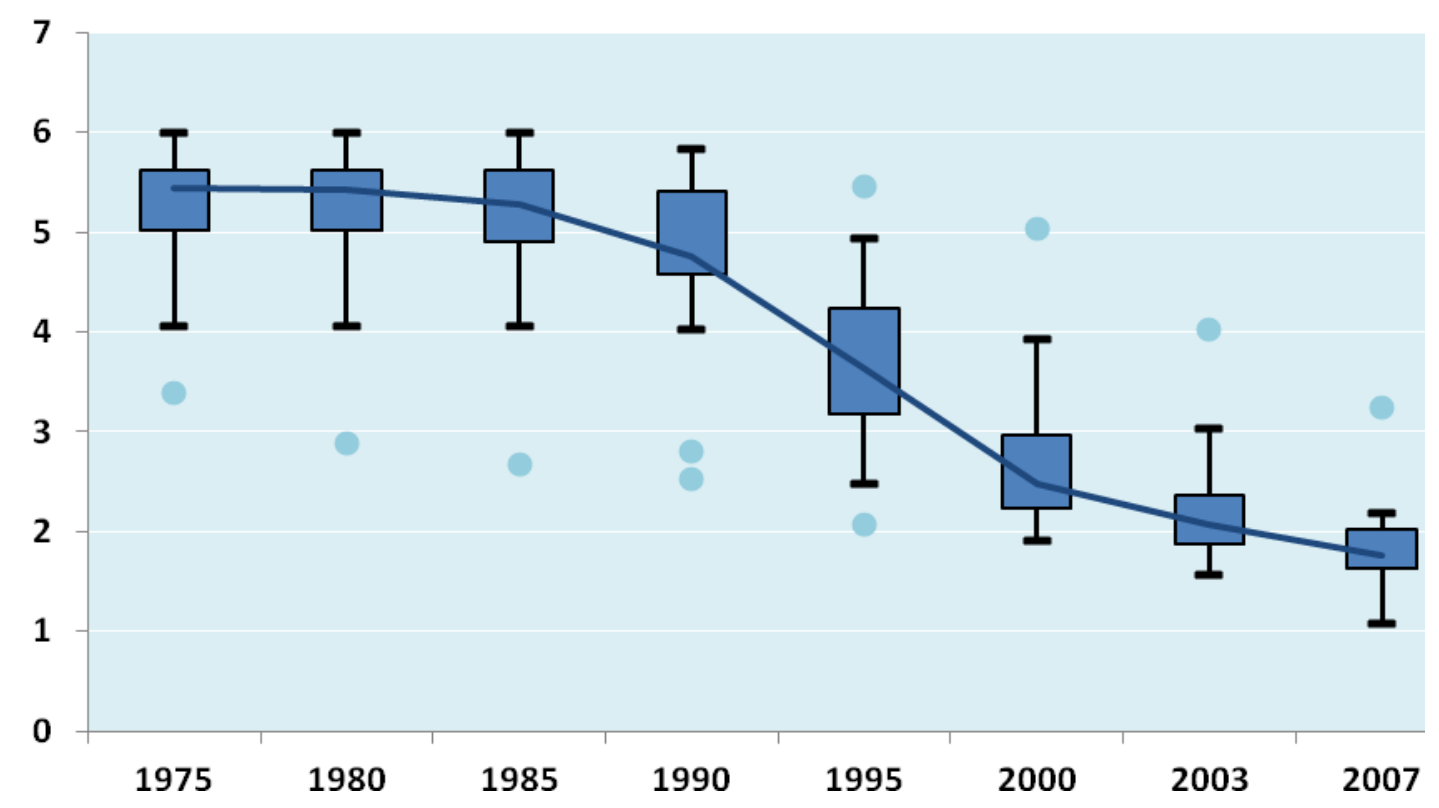

B. Regulation in retail trade, professional services and banking, 2003

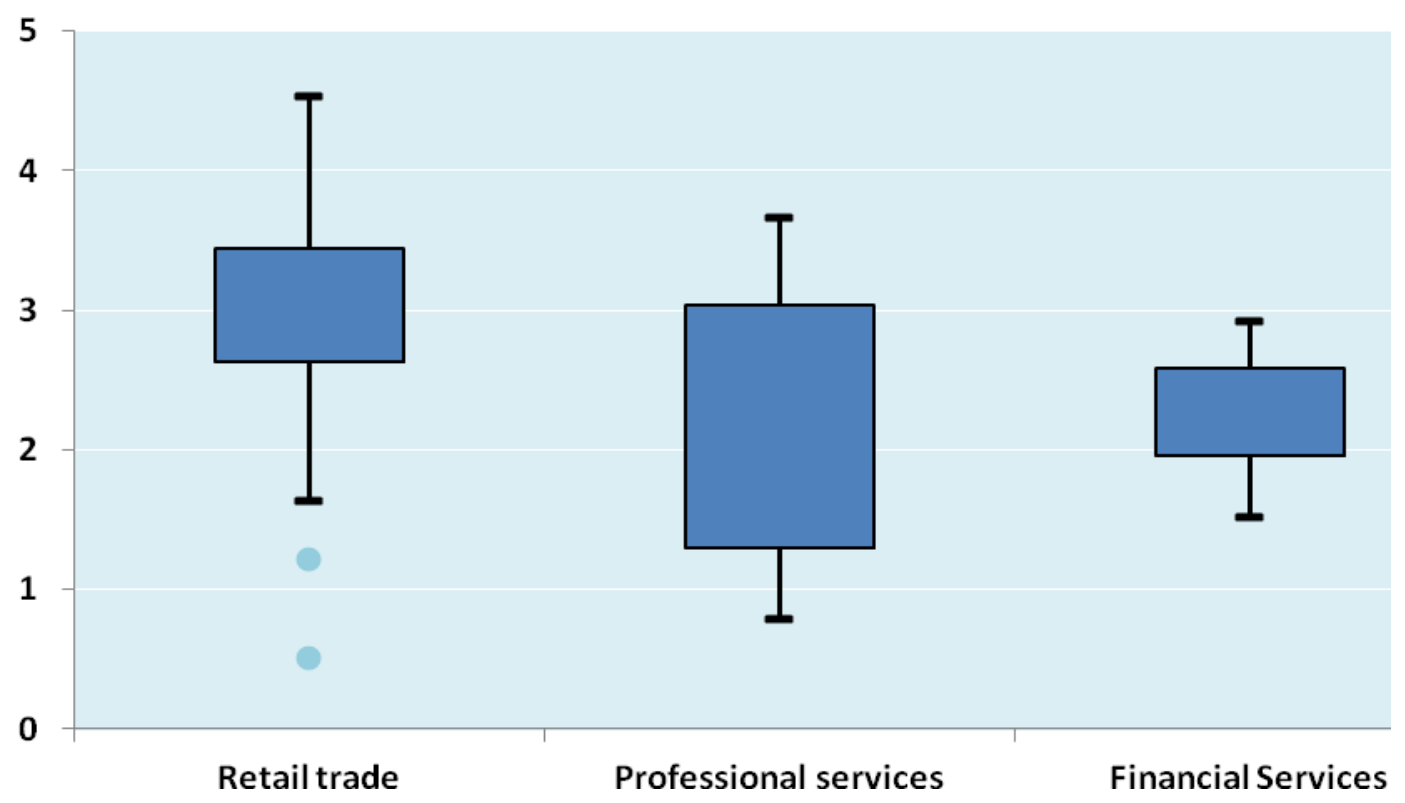


Figure 2. Variability of the 'regulatory burden' indicators and 'best practice' (0-1 scale from least to most restrictive)

A. Sample average by country in 1985,2000 and 2007

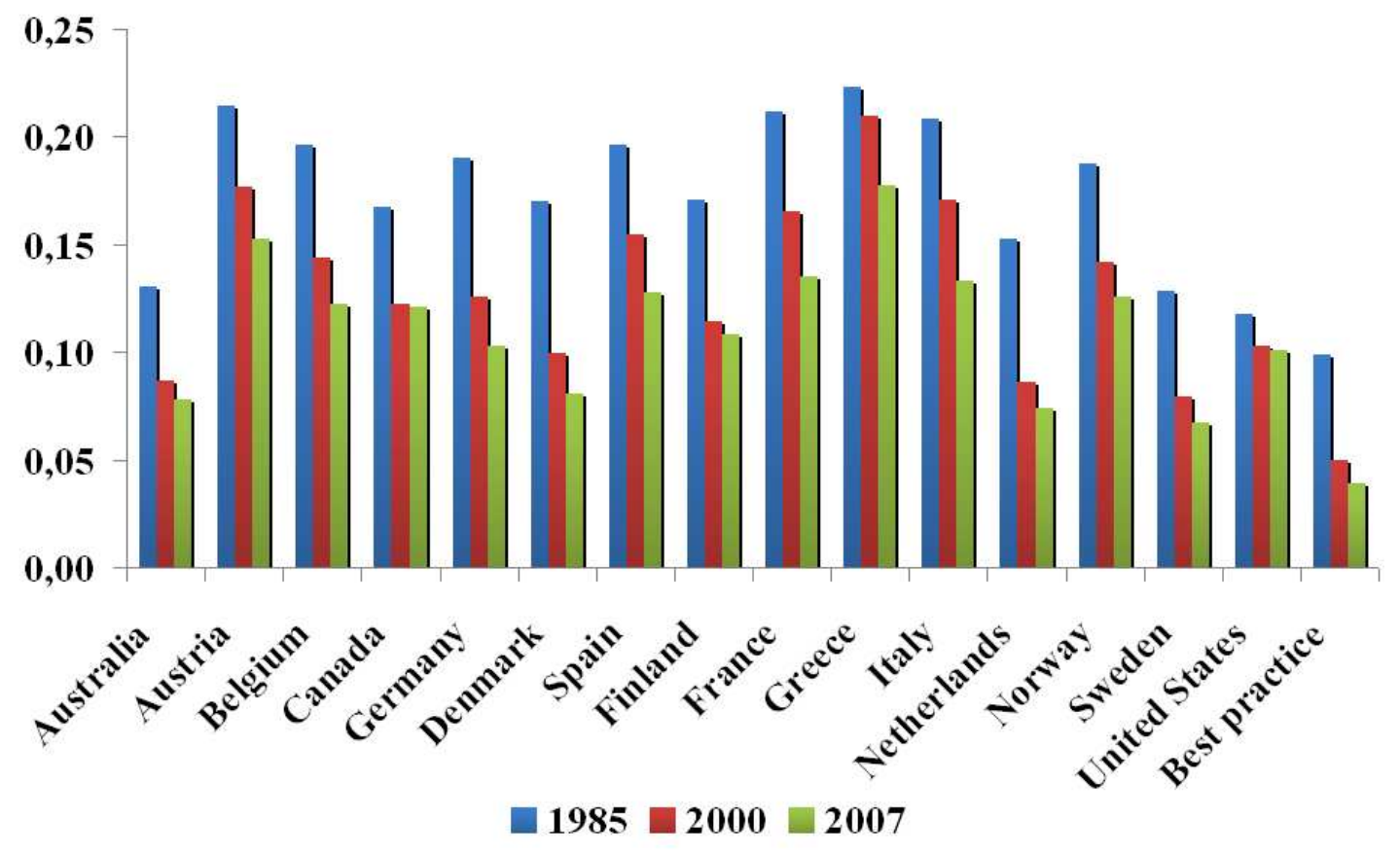

B. Sample average by industry in 2000 and 2007

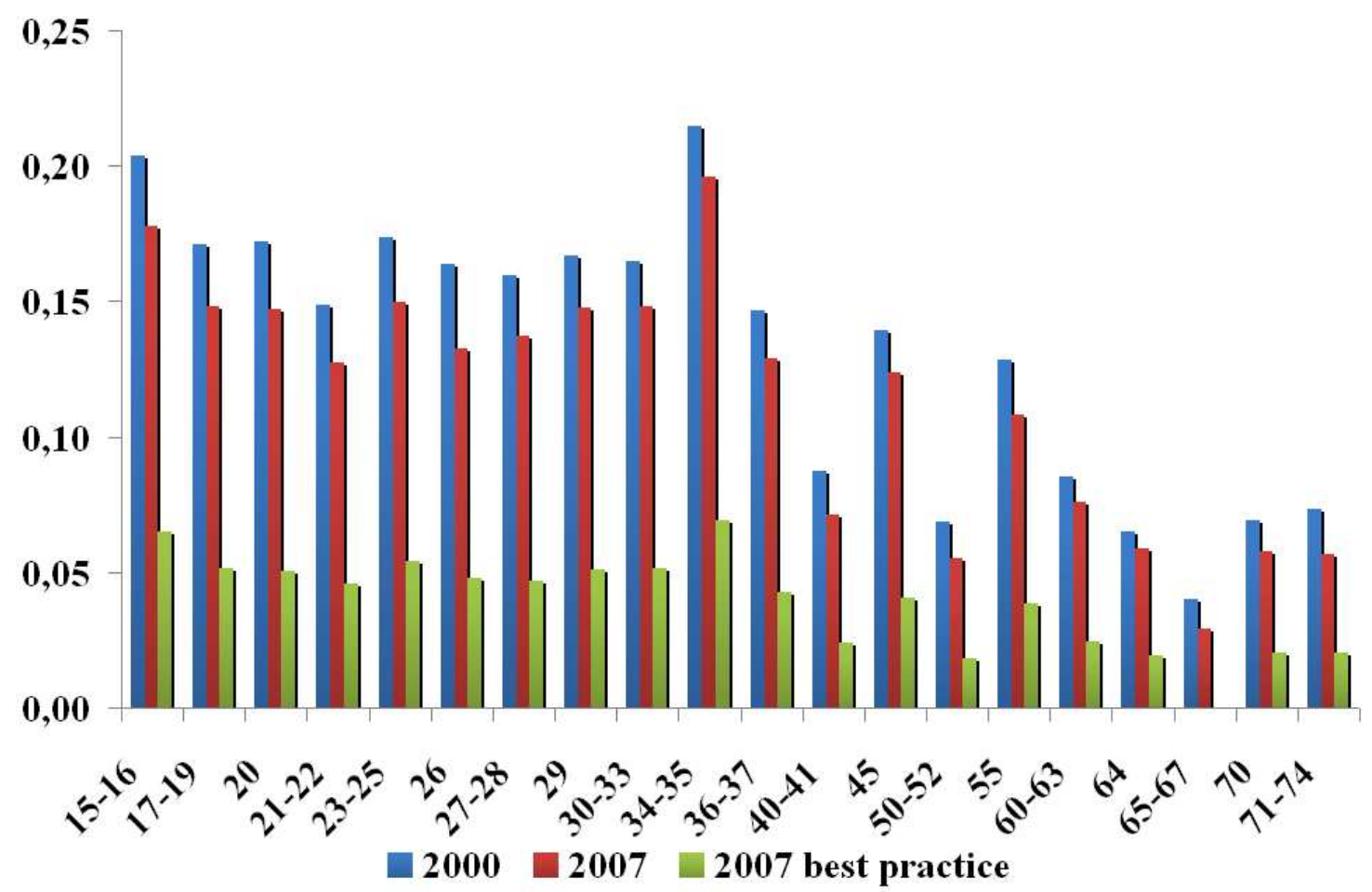

Sectors : 40-41 : Electricity, Gas and Water Supply ; 50-52 : Wholesale and Retail Trade, Repairs ; 60-63 : Transport and Storage ; 64 : Post and Telecommunications ; 65-67 : Financial Intermediation ; 71-74 : Renting of Material and Equipment and Other Business Activity. 
Figure 3. MFP growth and level, trends and cross country-industry dispersion

A. Average MFP growth over time and cross country-industry dispersion

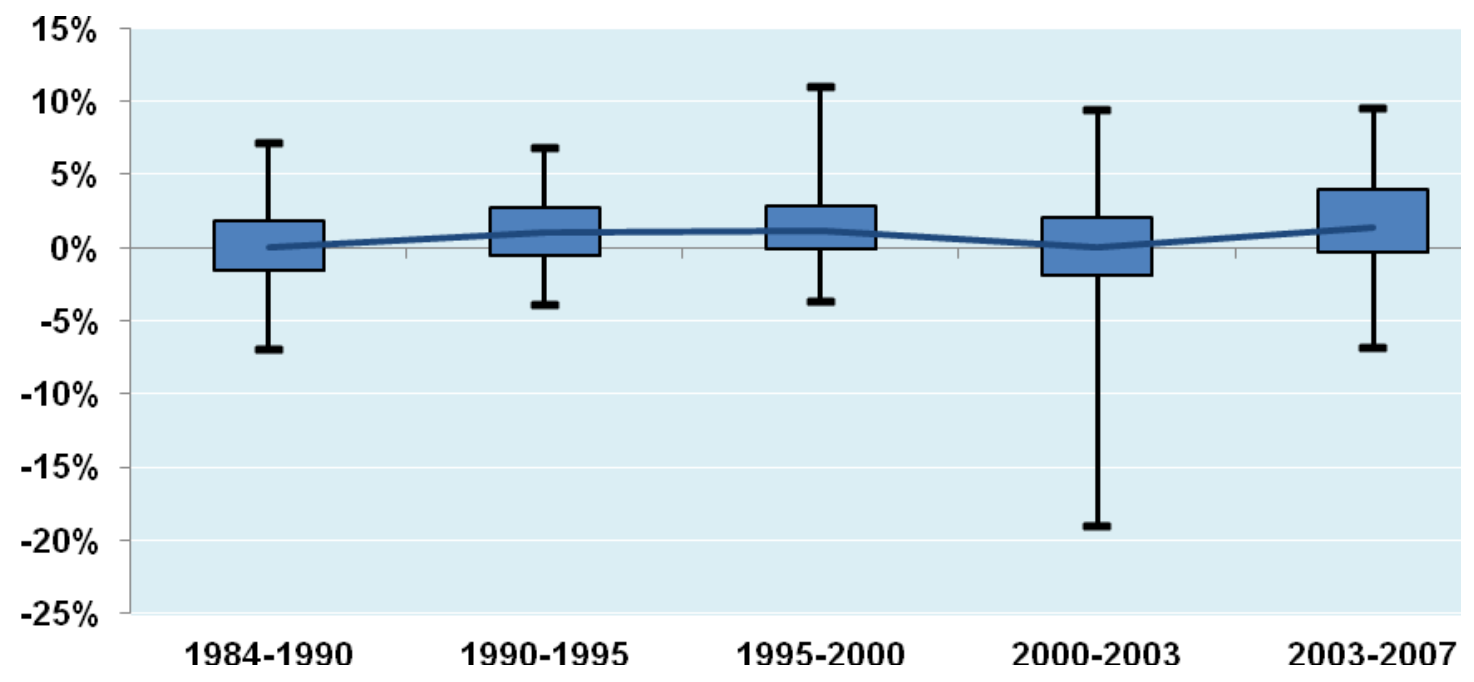

B. Ratio of the leading country MFP to the MFP of its followers, trends and cross countryindustry dispersion

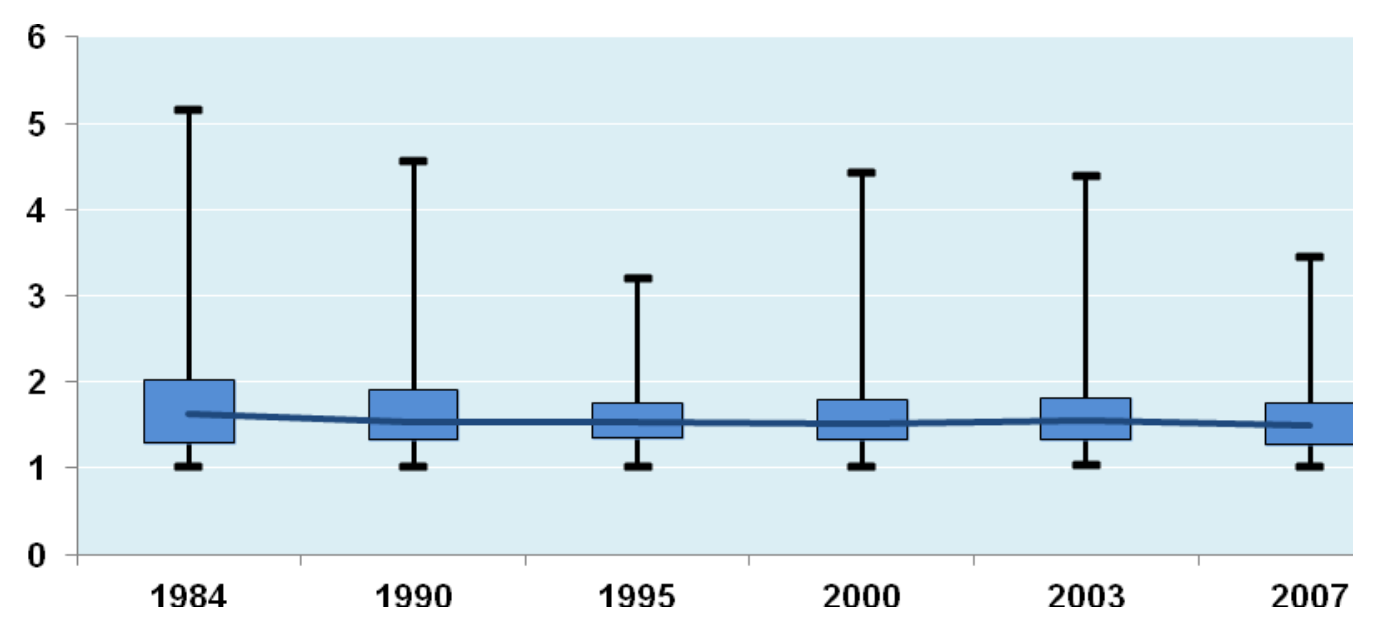


Figure 4. Regulation impact on MFP growth, 1985-2007, 85-94 and 95-07 estimates ${ }^{1}$

A. Regulation impact on MFP growth, 1985-2007 estimates

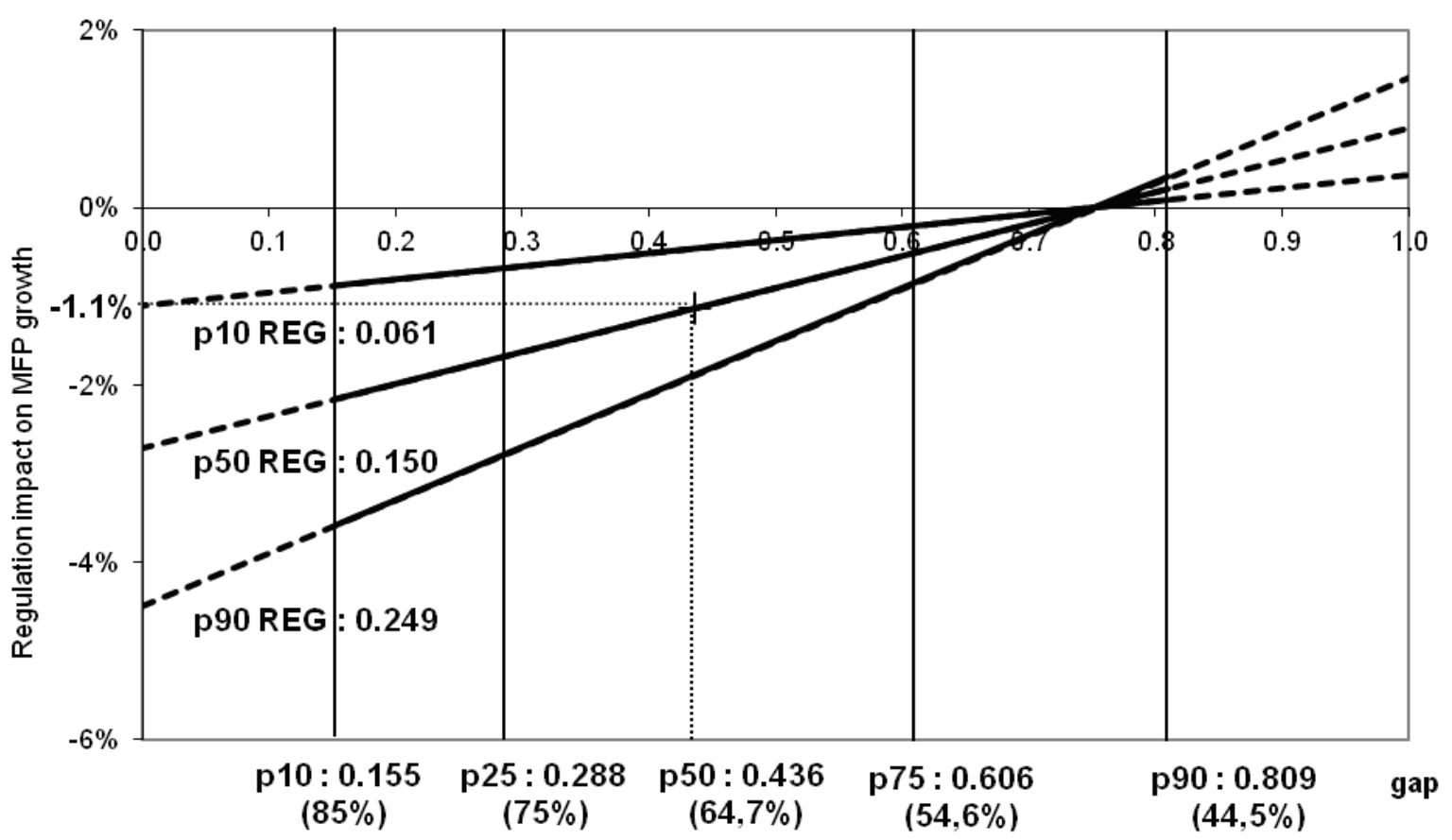

B. Regulation impact on MFP growth, 1985-1994 estimates

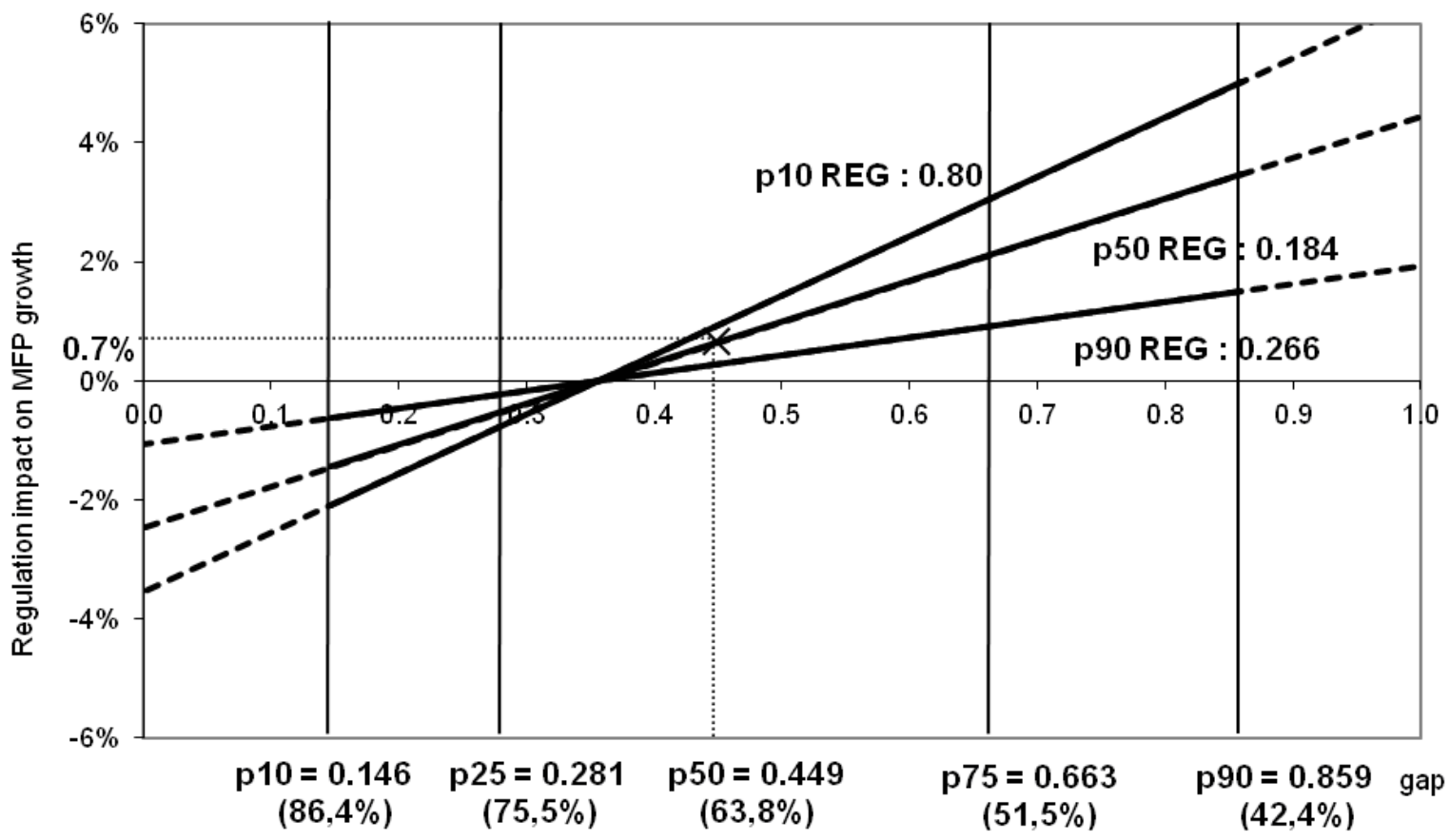




\section{C.Regulation impact on MFP growth, 1995-2007 estimates}

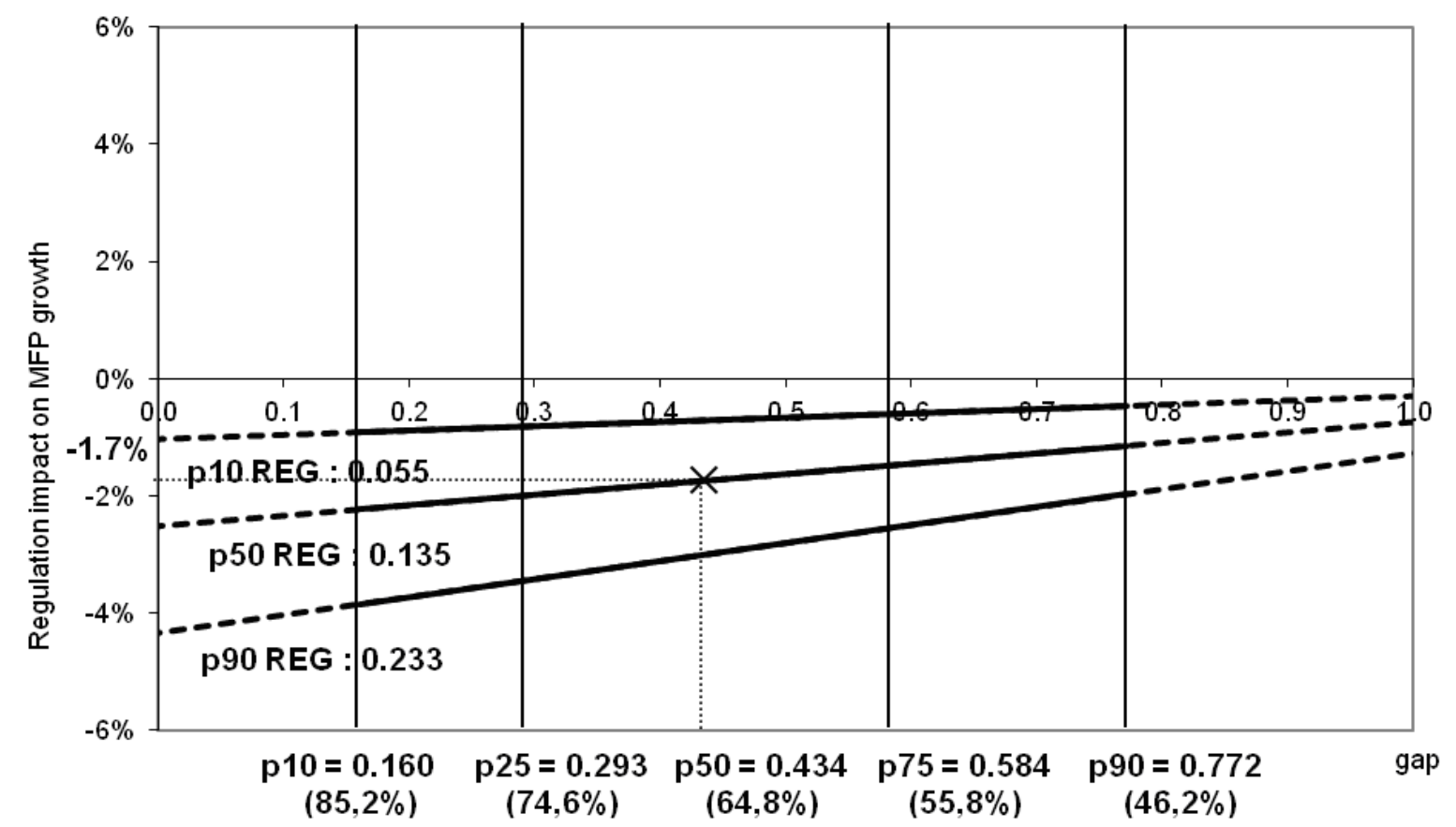

The impact of the regulatory burden on MFP growth depends of the country-industry pair distance from the industry frontier. This effect is introduced through the variable gap, which is the logarithm of the ratio of the industry MFP leader to the MFP of its followers. The quartiles as well as the first and last deciles of this variable are indicated on the figures (the corresponding percentage ratios of follower MFP to frontier MFP are in brackets). The first and last deciles of the regulatory burden indicator (REG) are also put on the figures, so the quadrangle included between these deciles and the ones of gap represent around $60 \%$ of the sample. 
Figure 5. Anticompetitive regulations levels in the upstream sectors in 2007 and 2007

(all sectoral indicators have a 0-6 range from least to most restrictive)

A. Anticompetitive regulations levels in the upstream sectors - 2000

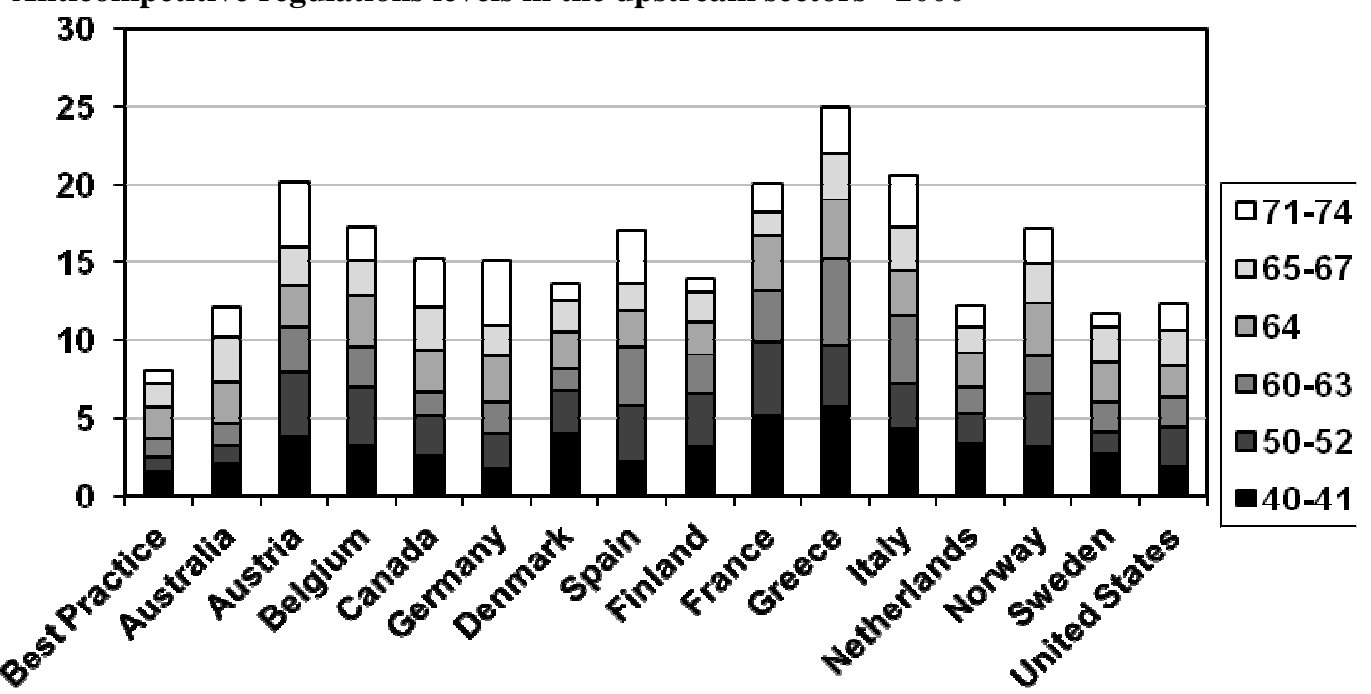

B. Anticompetitive regulations levels in the upstream sectors - 2007

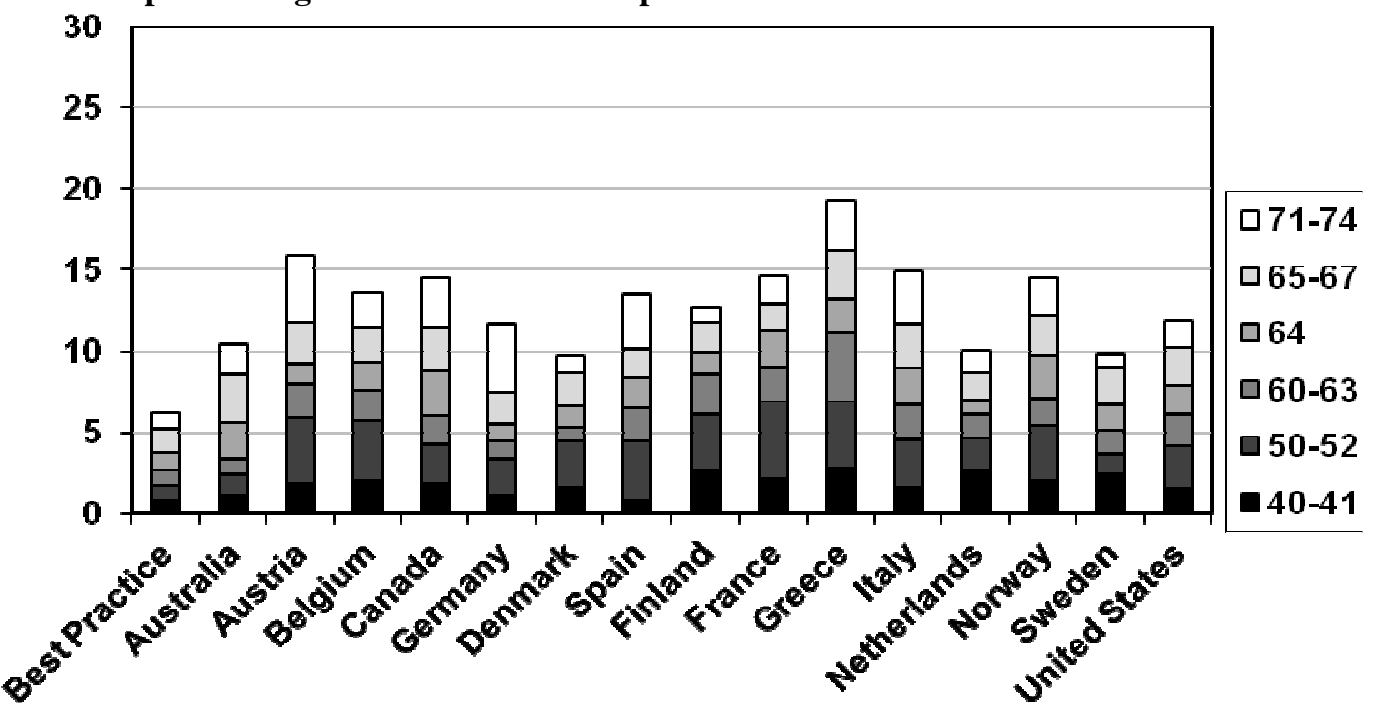

Sectors : 40-41 : Electricity, Gas and Water Supply ; 50-52 : Wholesale and Retail Trade, Repairs ; 60-63 : Transport and Storage ; 64 : Post and Telecommunications ; 65-67 : Financial Intermediation ; 71-74 : Renting of Material and Equipment and Other Business Activity. 
Figure 6. MFP gains in the non-farm business sector in $\mathbf{2 0 0 7}$

from adopting in 2000 the best practice observed in 2007 in the upstream sectors

A. MFP gains in 2007 - Alternative and simultaneous reforms

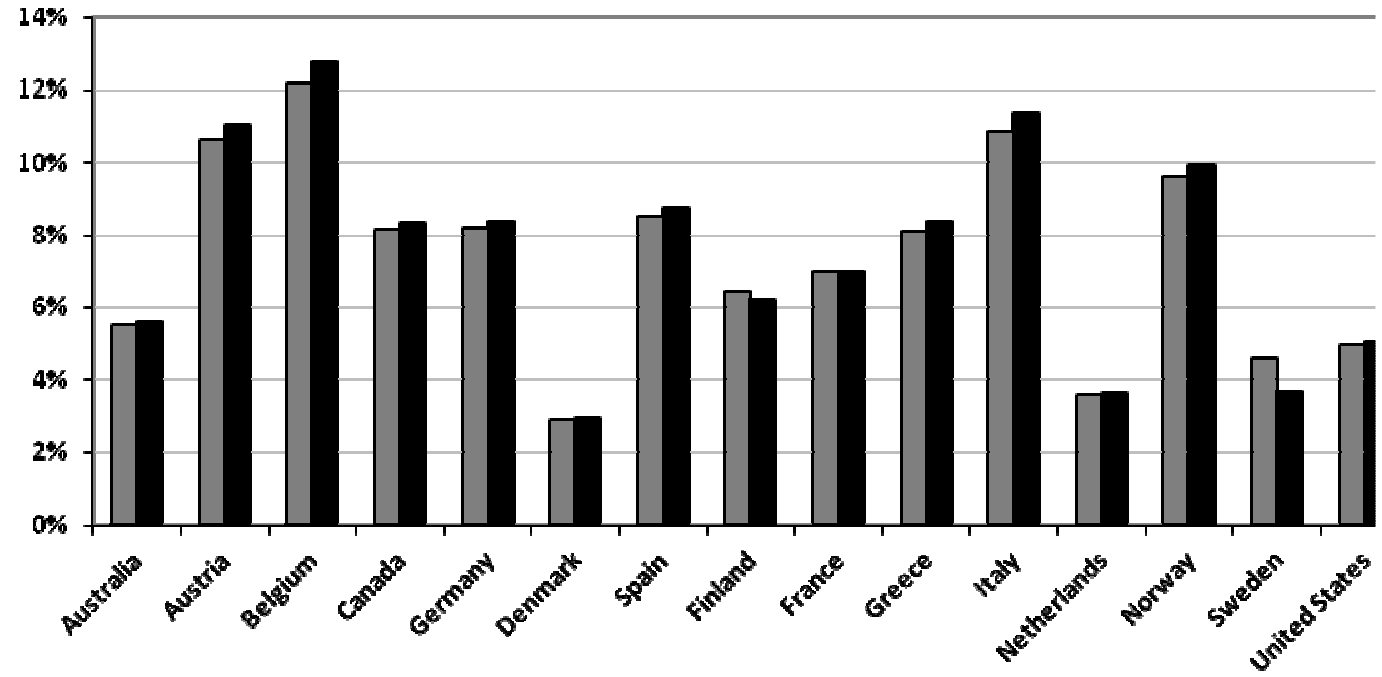

$\square$ Alternative reforms $\square$ Simultaneous reforms

B. Decomposition of the MFP gains in 2007 by upstream sectors

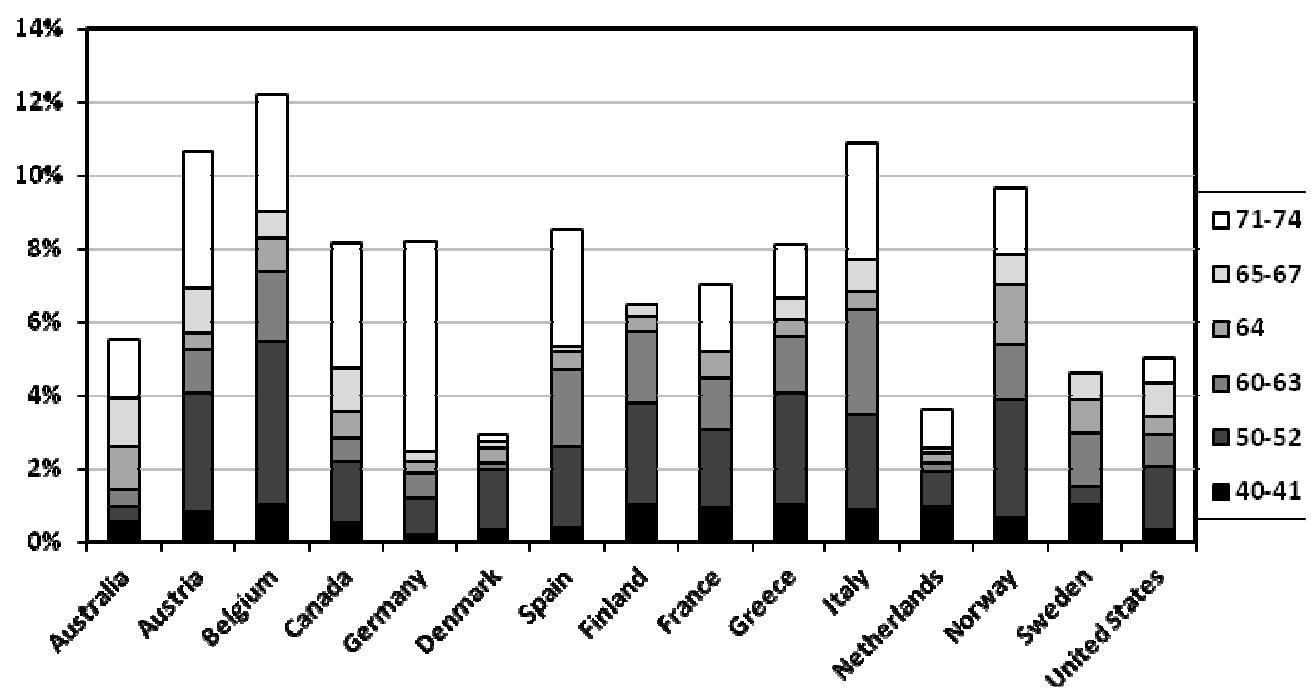

Sectors : 40-41 : Electricity, Gas and Water Supply ; 50-52 : Wholesale and Retail Trade, Repairs ; 60-63 : Transport and Storage ; 64 : Post and Telecommunications ; 65-67 : Financial Intermediation ; 71-74 : Renting of Material and Equipment and Other Business Activity. 
Figure 7. Annual gains in MFP growth in selected countries from adopting in 2000 the best practice observed in 2007 in the upstream sectors

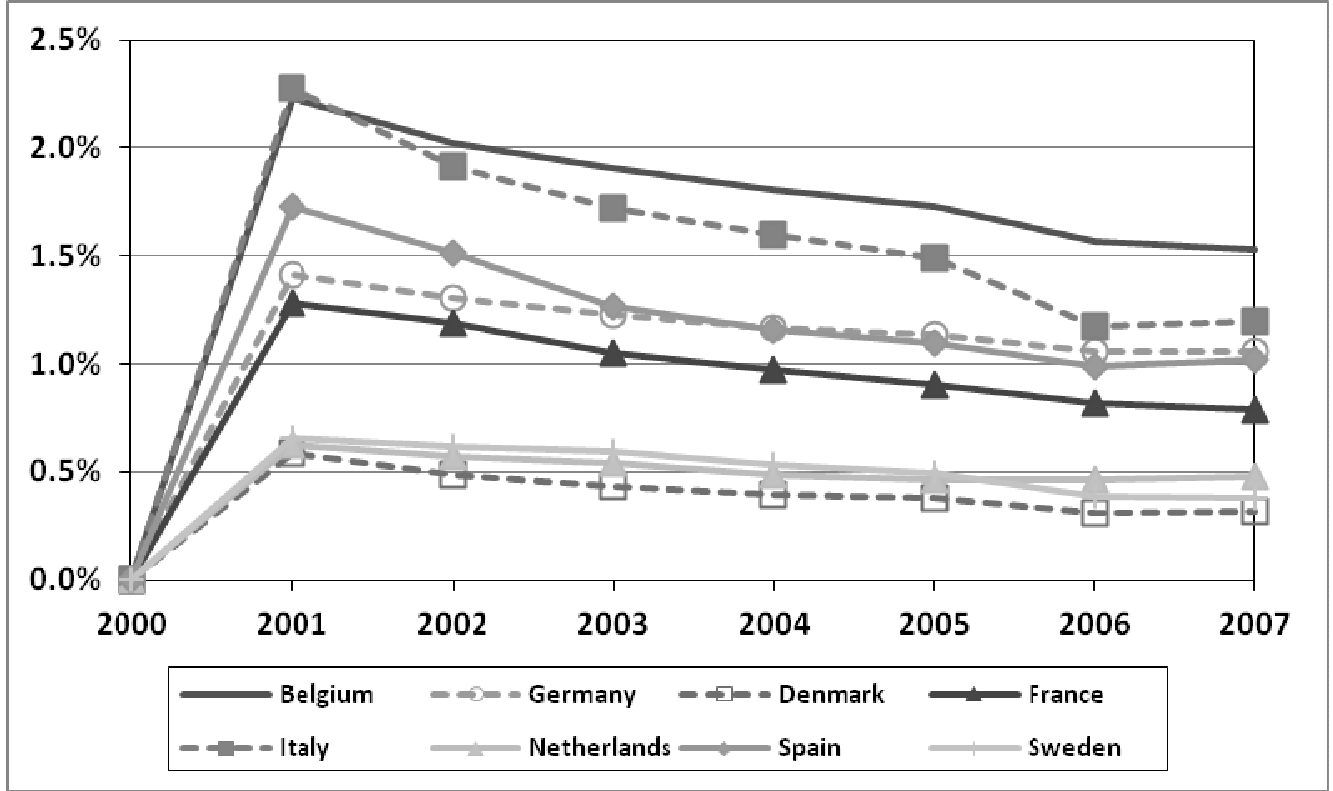


Table 1: Main estimation results

Dependent variable: Growth in multi-factor productivity (MFP)

\begin{tabular}{|c|c|c|c|c|}
\hline & & & & \\
\hline & $1985-2007$ & $1985-2007$ & $1985-1994$ & $1995-2007$ \\
\hline Change in MFP in the technology leader ${ }_{t}$ & $\begin{array}{c}0.113 * * * \\
{[0.016]}\end{array}$ & $\begin{array}{c}0.114 * * * \\
{[0.016]}\end{array}$ & $\begin{array}{l}0.065^{*} \\
{[0.033]}\end{array}$ & $\begin{array}{c}0.122 * * * \\
{[0.019]}\end{array}$ \\
\hline Gap in MFP levels $\mathrm{t}_{\mathrm{t}-1}$ & $\begin{array}{c}0.037 * * * \\
{[0.003]}\end{array}$ & $\begin{array}{c}0.041 * * * \\
{[0.004]}\end{array}$ & $\begin{array}{c}0.065 * * * \\
{[0.006]}\end{array}$ & $\begin{array}{c}0.032 * * * \\
{[0.005]}\end{array}$ \\
\hline Regulatory burden' indicators $\mathrm{t}_{\mathrm{t}-1}$ & $\begin{array}{l}-0.064 \\
{[0.048]}\end{array}$ & $\begin{array}{l}-0.067 \\
{[0.047]}\end{array}$ & $\begin{array}{c}0.044 \\
{[0.091]}\end{array}$ & $\begin{array}{c}-0.124 * * \\
{[0.062]}\end{array}$ \\
\hline Effect of gap on the regulation impact $t_{t-1}$ & & $\begin{array}{c}0.240 * * * \\
{[0.040]}\end{array}$ & $\begin{array}{c}0.375 * * * \\
{[0.064]}\end{array}$ & $\begin{array}{l}0.132 * * \\
{[0.054]}\end{array}$ \\
\hline Fixed effects : & & & \\
\hline Time $*$ Country & Yes & Yes & \multirow{2}{*}{\multicolumn{2}{|c|}{$\begin{array}{l}\text { Yes } \\
\text { Yes }\end{array}$}} \\
\hline Industry & Yes & Yes & & \\
\hline $\begin{array}{l}\text { Tests of joint significance (p-values): } \\
\text { gap }_{-1}=\mathrm{REG}_{-1}=\text { gap }_{-1} * \mathrm{REG}_{-1}=0\end{array}$ & & $\begin{array}{l}0.000 \\
0.000\end{array}$ & $\begin{array}{l}0.000 \\
0.000\end{array}$ & 0.000 \\
\hline $\mathrm{REG}_{-1}=\mathrm{gap}_{-1} * \mathrm{REG}_{-1}=0$ & & 0.000 & 0.000 & 0.011 \\
\hline $\begin{array}{l}\text { Test of equality across both periods (p-values, } \\
\text { joint for gap-1, REG- } 1 \text { and gap- } 1 * \text { REG- } 1\end{array}$ & & & \multicolumn{2}{|c|}{0.000} \\
\hline \multicolumn{3}{|c|}{ Ratio $\mathrm{MFP}_{\mathrm{F}}$ on MFP above which $\mathrm{REG}_{-1}$ has a positive impact } & & \\
\hline Ratio & & $2.123 * * *$ & $1.425 * * *$ & $4.115^{*}$ \\
\hline Proportion of the sample above this threshold & & $13.22 \%$ & $63.10 \%$ & $1.40 \%$ \\
\hline Observations & 4629 & 4629 & 1691 & 2938 \\
\hline R-squared & 0.25 & 0.25 & \multicolumn{2}{|c|}{0.27} \\
\hline
\end{tabular}

Standard errors in brackets

* significant at $10 \%$;* significant at $5 \%$; *** significant at $1 \%$ 
Figure A2.1 The correspondence between the indicators of non-manufacturing and ISIC sectors

ISIC sectors


Figure A2.2 Industry list ${ }^{1}$

\begin{tabular}{|l|c|}
\hline FOOD PRODUCTS, BEVERAGES AND TOBACCO & $15-16$ \\
\hline TEXTILES, TEXTILE PRODUCTS, LEATHER AND FOOTWEAR & $17-19$ \\
\hline WOOD AND PRODUCTS OF WOOD AND CORK & 20 \\
\hline PULP, PAPER, PAPER PRODUCTS, PRINTING AND PUBLISHING & $21-22$ \\
\hline CHEMICAL, RUBBER, PLASTICS AND FUEL PRODUCTS & $23-25$ \\
\hline OTHER NON-METALLIC MINERAL PRODUCTS & 26 \\
\hline BASIC METALS AND FABRICATED METAL PRODUCTS & $27-28$ \\
\hline MACHINERY AND EQUIPMENT, N.E.C. & 29 \\
\hline ELECTRICAL AND OPTICAL EQUIPMENT & $30-33$ \\
\hline TRANSPORT EQUIPMENT & $34-35$ \\
\hline MANUFACTURING NEC; RECYCLING & $36-37$ \\
\hline ELECTRICITY GAS AND WATER SUPPLY (Energy) & $40-41$ \\
\hline CONSTRUCTION & 45 \\
\hline WHOLESALE AND RETAIL TRADE; REPAIRS (Retail) & $50-52$ \\
\hline HOTELS AND RESTAURANTS & 55 \\
\hline TRANSPORT AND STORAGE (TranSPOrt) & $60-63$ \\
\hline POST AND TELECOMMUNICATIONS (Com.) & 64 \\
\hline FINANCIAL INTERMEDIATION (Fin. S.) & $65-67$ \\
\hline REAL ESTATE ACTIVITIES & 70 \\
\hline RENTING OF M\&EQ AND OTHER BUSINESS ACTIVITIES (Prof. S.) & $71-74$ \\
\hline
\end{tabular}

1. "Upstream"sectors for which regulation data are available are in red. 
Table A3-1

Estimation on a moving 15 year time period window - Period: 1995-2007

\begin{tabular}{|c|c|c|c|c|c|c|c|c|c|}
\hline & 1985-1999 & 1986-2000 & 1987-2001 & 1988-2002 & 1989-2003 & 1990-2004 & 1991-2005 & 1992-2006 & 1993-2007 \\
\hline$\Delta \ln \left(\mathbf{M F P}_{\mathrm{F}}\right)$ & $\begin{array}{c}0.089 * * * \\
{[0.023]}\end{array}$ & $\begin{array}{c}0.097 * * * \\
{[0.021]}\end{array}$ & $\begin{array}{c}0.127 * * * \\
{[0.019]}\end{array}$ & \begin{tabular}{|c|}
$0.134 * * *$ \\
{$[0.019]$}
\end{tabular} & $\begin{array}{c}0.137 * * * \\
{[0.018]}\end{array}$ & $\begin{array}{c}0.140 * * * \\
{[0.018]}\end{array}$ & $\begin{array}{c}0.137 * * * \\
{[0.018]}\end{array}$ & $\begin{array}{c}0.115 * * * \\
{[0.018]}\end{array}$ & $\begin{array}{c}0.120 * * * \\
{[0.019]}\end{array}$ \\
\hline gap.1 $_{-1}$ & $0.056^{* * * *}$ & $\begin{array}{c}0.053 * * * \\
{[0.004]}\end{array}$ & $0.045^{* * * *}$ & $0.040 * * *$ & $0.040^{* * * *}$ & $0.036 * * *$ & $0.035^{* * * *}$ & $0.034 * * *$ & $0.034 * * *$ \\
\hline REG $_{-1}$ & $\begin{array}{c}0,012 \\
{[0.061]}\end{array}$ & $\begin{array}{l}-0,015 \\
{[0.058]}\end{array}$ & $\begin{array}{l}-0,019 \\
{[0.058]}\end{array}$ & $\begin{array}{c}-0,021 \\
{[0.057]}\end{array}$ & $\begin{array}{c}-0,051 \\
{[0.056]}\end{array}$ & $\begin{array}{c}-0,077 \\
{[0.056]}\end{array}$ & $\begin{array}{c}-0.099^{*} \\
{[0.056]}\end{array}$ & $\begin{array}{l}-0.102 * \\
{[0.056]}\end{array}$ & $\begin{array}{c}-0.116^{* *} \\
{[0.058]}\end{array}$ \\
\hline $\operatorname{gap}_{-1} * \mathbf{R E G}_{-1}$ & $\begin{array}{c}0.230 * * * \\
{[0.049]}\end{array}$ & $\begin{array}{c}0.250 * * * \\
{[0.047]}\end{array}$ & $\begin{array}{c}0.246 * * * \\
{[0.049]}\end{array}$ & $\begin{array}{c}0.227 * * * \\
{[0.050]}\end{array}$ & $\begin{array}{c}0.227 * * * \\
{[0.049]}\end{array}$ & $\begin{array}{c}0.167 * * * \\
{[0.050]}\end{array}$ & $\begin{array}{c}0.178 * * * \\
{[0.049]}\end{array}$ & $\begin{array}{c}0.175 * * * \\
{[0.050]}\end{array}$ & $\begin{array}{c}0.170 * * * \\
{[0.051]}\end{array}$ \\
\hline $\begin{array}{l}\text { Fixed effects: } \\
\text { Time * Country } \\
\text { Industry }\end{array}$ & $\begin{array}{l}\text { Yes } \\
\text { Yes }\end{array}$ & & & & $\begin{array}{l}\text { Yes } \\
\text { Yes }\end{array}$ & & & & $\begin{array}{l}\text { Yes } \\
\text { Yes }\end{array}$ \\
\hline Obse & 2906 & 31. & 32 & 3318 & 3385 & 34 & 3511 & 3510 & 3378 \\
\hline R-squared & 0,29 & 0,29 & 0,27 & 0,26 & 0,26 & 0,26 & 0,26 & 0,24 & 0,24 \\
\hline
\end{tabular}

Standard errors in brackets

* significant at $10 \%$; ** significant at $5 \% ; * * *$ significant at $1 \%$

Table A3-2

One country is alternatively dropped from the dataset - Period: 1995-2007

\begin{tabular}{|c|c|c|c|c|c|c|c|c|c|c|c|c|c|c|c|c|}
\hline & \begin{tabular}{c|c|} 
Main \\
estimation
\end{tabular} & AUS & AUT & BEL & CAN & DEU & DNK & ESP & FIN & FRA & GRC & ITA & NLD & NOR & SWE & USA \\
\hline$\Delta \ln \left(\mathbf{M F P}_{\mathrm{F}}\right)$ & $\begin{array}{c}0.121 * * * \\
{[0.019]}\end{array}$ & $\begin{array}{c}0.122 * * * \\
{[0.019]} \\
-\end{array}$ & $\begin{array}{c}0.132 * * * \\
{[0.020]}\end{array}$ & $\begin{array}{c}0.120 * * * \\
{[0.020]} \\
-\end{array}$ & \begin{tabular}{|c|}
$0.119 * * *$ \\
{$[0.020]$} \\
-
\end{tabular} & $\begin{array}{c}0.118^{* * * *} \\
{[0.020]} \\
-\end{array}$ & \begin{tabular}{|c|}
$0.127 * * *$ \\
{$[0.019]$} \\
-
\end{tabular} & $\begin{array}{c}0.123 * * * \\
{[0.020]} \\
-\end{array}$ & $\begin{array}{c}0.125 * * * \\
{[0.019]} \\
-\end{array}$ & $\begin{array}{c}0.119 * * * \\
{[0.020]} \\
-\end{array}$ & $\begin{array}{c}0.137 * * * \\
{[0.019]} \\
-\end{array}$ & \begin{tabular}{|c|}
$0.129 * * *$ \\
{$[0.020]$} \\
-
\end{tabular} & \begin{tabular}{|c|}
$0.111 * * *$ \\
{$[0.020]$} \\
-
\end{tabular} & $\begin{array}{c}0.113^{* * * *} \\
{[0.019]} \\
-\end{array}$ & \begin{tabular}{|c|}
$0.117 * * *$ \\
{$[0.019]$} \\
-
\end{tabular} & $\begin{array}{c}0.112^{* * * *} \\
{[0.020]} \\
-\end{array}$ \\
\hline gap. $_{-1}$ & $\begin{array}{c}0.032 * * * \\
{[0.005]}\end{array}$ & $\begin{array}{c}0.032 * * * \\
{[0.005]}\end{array}$ & $\begin{array}{c}0.034 * * * \\
{[0.005]}\end{array}$ & $\begin{array}{c}0.031 * * * \\
{[0.005]}\end{array}$ & $\begin{array}{c}0.034 * * * \\
{[0.005]}\end{array}$ & $\begin{array}{c}0.031 * * * \\
{[0.005]}\end{array}$ & $\begin{array}{c}0.029 * * * \\
{[0.005]}\end{array}$ & $\begin{array}{c}0.034 * * * \\
{[0.005]}\end{array}$ & $\begin{array}{c}0.036^{* * * *} \\
{[0.005]}\end{array}$ & $\begin{array}{c}0.032 * * * \\
{[0.005]}\end{array}$ & $\begin{array}{c}0.035 * * * \\
{[0.006]}\end{array}$ & $\begin{array}{c}0.036 * * * \\
{[0.005]}\end{array}$ & $\begin{array}{c}0.032 * * * \\
{[0.005]}\end{array}$ & $\begin{array}{c}0.030 * * * \\
{[0.005]}\end{array}$ & $\begin{array}{c}0.033 * * * \\
{[0.005]}\end{array}$ & $\begin{array}{c}0.032 * * * \\
{[0.005]}\end{array}$ \\
\hline REG $_{-1}$ & $\begin{array}{c}-0.124 * * \\
{[0.062]}\end{array}$ & $\begin{array}{c}-0.126 * * \\
{[0.063]}\end{array}$ & $\begin{array}{c}-0.248 * * * \\
{[0.069]}\end{array}$ & $\begin{array}{c}-0.125^{* *} \\
{[0.064]}\end{array}$ & $\begin{array}{c}-0,105 \\
{[0.064]}\end{array}$ & $\begin{array}{c}-0,105 \\
{[0.065]}\end{array}$ & $\begin{array}{c}-0.138 * * \\
{[0.063]}\end{array}$ & $\begin{array}{l}-0.128^{*} \\
{[0.066]}\end{array}$ & $\begin{array}{l}-0.108^{*} \\
{[0.063]}\end{array}$ & $\begin{array}{c}-0.142^{* *} \\
{[0.067]}\end{array}$ & $\begin{array}{l}-0,088 \\
{[0.063]}\end{array}$ & $\begin{array}{c}-0.111^{*} \\
{[0.065]}\end{array}$ & $\begin{array}{c}-0,109 \\
{[0.067]}\end{array}$ & $\begin{array}{c}-0.107^{*} \\
{[0.059]}\end{array}$ & $\begin{array}{c}-0,09 \\
{[0.071]}\end{array}$ & $\begin{array}{c}-0.130^{* * *} \\
{[0.063]}\end{array}$ \\
\hline $\operatorname{gap}_{-1} * \mathbf{R E G}_{-1}$ & $\begin{array}{l}0.132 * * \\
{[0.054]}\end{array}$ & & $\begin{array}{c}0.134 * * \\
{[0.055]}\end{array}$ & & & & & & $\begin{array}{c}0,085 \\
{[0.061]}\end{array}$ & & $\begin{array}{c}0.210^{* * * *} \\
{[0.066]}\end{array}$ & $\begin{array}{c}0.153 * * * \\
{[0.058]}\end{array}$ & & & & \\
\hline & & & & & & & & & & & $\begin{array}{l}\text { Yes } \\
\text { Yes }\end{array}$ & $\begin{array}{l}\text { Yes } \\
\text { Yes }\end{array}$ & & & & $\begin{array}{l}\text { Yes } \\
\text { Yes }\end{array}$ \\
\hline & & & & & & & & & & 100 & & & & & & 2827 \\
\hline R-squared & 0,22 & 0,21 & 0,23 & 0,22 & 0,22 & 0,21 & 0,22 & 0,21 & 0,21 & 0,21 & 0,22 & 0,21 & 0,21 & 0,23 & 0,21 & 0,21 \\
\hline
\end{tabular}

Standard errors in brackets

* significant at $10 \%$;* significant at $5 \%$; *** significant at $1 \%$ 
Table A3-3

One sector is alternatively dropped from the dataset - Period: 1995-2007

\begin{tabular}{|c|c|c|c|c|c|c|c|c|c|c|c|c|c|c|c|c|c|c|c|c|}
\hline & $\begin{array}{c}\text { Main } \\
\text { estimation }\end{array}$ & $15-16$ & $17-19$ & 20 & $21-22$ & $23-25$ & 26 & $27-28$ & 29 & 30-33 & 34-35 & 36-37 & $40-41$ & 45 & $50-52$ & 55 & $60-63$ & 64 & $65-67$ & 70 \\
\hline$\Delta \ln \left(\mathbf{M F P}_{\mathrm{F}}\right)$ & $\begin{array}{c}0.121 * * * \\
{[0.019]}\end{array}$ & $\begin{array}{c}0.126 * * * \\
{[0.020]}\end{array}$ & {$\left[\begin{array}{c}0.125 * * * \\
{[0.019]}\end{array}\right.$} & $\begin{array}{c}0.126 * * * \\
{[0.019]}\end{array}$ & $\begin{array}{c}0.118 * * * * \\
{[0.020]}\end{array}$ & $\mid \begin{array}{c}0.130 * * * \\
{[0.019]}\end{array}$ & $\begin{array}{c}0.125 * * * \\
{[0.019]}\end{array}$ & $\begin{array}{c}0.119 * * * \\
{[0.019]}\end{array}$ & $\begin{array}{c}0.114 * * * \\
{[0.019]}\end{array}$ & $\begin{array}{c}0.076 * * * \\
{[0.022]}\end{array}$ & $\mid \begin{array}{c}0.132 * * * * \\
{[0.019]}\end{array}$ & $\left|\begin{array}{c}0.122 * * * \\
{[0.019]}\end{array}\right|$ & $\begin{array}{c}0.120 * * * \\
{[0.019]}\end{array}$ & $\begin{array}{c}0.123 * * * \\
{[0.020]}\end{array}$ & & & & & & \\
\hline gap $_{-1}$ & $0.032 * * *$ & $0.034 * * *$ & $0.032 * * *$ & $0.030 * * *$ & $0.031 * * *$ & $0.032 * * *$ & $0.031 * * *$ & $0.031 * * *$ & $0.031 * * *$ & $0.031 * * *$ & $0.031 * * *$ & $0.032 * * *$ & $0.032 * * *$ & $0.032 * * *$ & $0.032 * * *$ & $0.034 * * *$ & $0.031 * * *$ & $0.033^{* * *}$ & $0.037 * * *$ & $0.034 * * *$ \\
\hline & {$[0.005]$} & {$[0.005]$} & {$[0.005]$} & {$[0.005]$} & {$[0.005]$} & {$[0.005]$} & {$[0.005]$} & {$[0.005]$} & {$[0.005]$} & {$[0.005]$} & {$[0.005]$} & {$[0.005]$} & {$[0.005]$} & {$[0.005]$} & {$[0.005]$} & {$[0.005]$} & {$[0.005]$} & {$[0.005]$} & {$[0.005]$} & {$[0.005]$} \\
\hline REG.1 & $\begin{array}{c}-0.124 * * \\
{[0.062]}\end{array}$ & $\begin{array}{c}-0,101 \\
{[0.066]}\end{array}$ & $\begin{array}{c}-0.149 * * \\
{[0.063]}\end{array}$ & $\begin{array}{c}-0.105^{*} \\
{[0.063]}\end{array}$ & $\begin{array}{c}-0.120^{*} \\
{[0.063]}\end{array}$ & $\begin{array}{c}-0.113^{*} \\
{[0.062]}\end{array}$ & $\begin{array}{c}-0.123^{*} \\
{[0.064]}\end{array}$ & $\begin{array}{l}-0.122^{*} \\
{[0.063]}\end{array}$ & $\begin{array}{c}-0.132 * * \\
{[0.063]}\end{array}$ & $\begin{array}{c}-0.134 * * \\
{[0.062]}\end{array}$ & \begin{tabular}{|c|}
$-0.131^{*}$ \\
{$[0.068]$}
\end{tabular} & $\begin{array}{c}-0.129 * * \\
{[0.062]}\end{array}$ & $\begin{array}{c}-0.104 * \\
{[0.063]}\end{array}$ & $\begin{array}{c}-0.118^{*} \\
{[0.064]}\end{array}$ & $\begin{array}{c}-0.170^{* * *} \\
{[0.068]}\end{array}$ & $\begin{array}{c}-0.111^{*} \\
{[0.064]}\end{array}$ & $\begin{array}{c}-0.117^{*} \\
{[0.064]}\end{array}$ & \begin{tabular}{|c}
$-0.143 * *$ \\
{$[0.064]$}
\end{tabular} & $\begin{array}{c}-0,068 \\
{[0.066]}\end{array}$ & $\begin{array}{c}-0.140 * * \\
{[0.066]}\end{array}$ \\
\hline gap $_{-1} *$ REG $_{-1}$ & $\begin{array}{c}0.132 * * \\
{[0.054]} \\
\end{array}$ & $\begin{array}{c}0.140 * * \\
{[0.055]}\end{array}$ & $\begin{array}{c}0.147 * * * \\
{[0.055]}\end{array}$ & $\begin{array}{c}0.134 * * \\
{[0.055]}\end{array}$ & $\begin{array}{c}0.129 * * \\
{[0.055]}\end{array}$ & $\begin{array}{c}0.137 * * \\
{[0.055]} \\
\end{array}$ & $\begin{array}{c}0.112 * * \\
{[0.055]}\end{array}$ & $\begin{array}{l}0.130 * * \\
{[0.055]}\end{array}$ & $\begin{array}{c}0.116^{* * *} \\
{[0.055]} \\
\end{array}$ & $\begin{array}{c}0.122 * * \\
{[0.054]}\end{array}$ & $\begin{array}{c}0.135 * * \\
{[0.057]} \\
\end{array}$ & $\begin{array}{c}0.153 * * * \\
{[0.057]}\end{array}$ & $\begin{array}{c}0.148 * * * \\
{[0.053]} \\
\end{array}$ & $\begin{array}{c}0.127 * * \\
{[0.055]}\end{array}$ & $\begin{array}{l}0.129 * * \\
{[0.056]}\end{array}$ & $\begin{array}{c}0.153 * * * \\
{[0.056]}\end{array}$ & {$\left[\begin{array}{c}0.147 * * * \\
{[0.055]}\end{array}\right.$} & $\begin{array}{l}0.129^{* *} \\
{[0.054]} \\
\end{array}$ & $\begin{array}{c}0,08 \\
{[0.068]}\end{array}$ & $\begin{array}{l}0.114^{* * *} \\
{[0.056]}\end{array}$ \\
\hline $\begin{array}{l}\text { Fixed eff.: } \\
\text { Time*Coun } \\
\text { t. } \\
\text { Industry } \\
\end{array}$ & $\begin{array}{l}\text { Yes } \\
\text { Yes }\end{array}$ & $\begin{array}{l}\text { Yes } \\
\text { Yes }\end{array}$ & $\begin{array}{l}\text { Yes } \\
\text { Yes }\end{array}$ & $\begin{array}{l}\text { Yes } \\
\text { Yes }\end{array}$ & $\begin{array}{l}\text { Yes } \\
\text { Yes }\end{array}$ & $\begin{array}{l}\text { Yes } \\
\text { Yes }\end{array}$ & $\begin{array}{l}\text { Yes } \\
\text { Yes }\end{array}$ & & $\begin{array}{l}\text { Yes } \\
\text { Yes }\end{array}$ & $\begin{array}{l}\text { Yes } \\
\text { Yes }\end{array}$ & & $\begin{array}{l}\text { Yes } \\
\text { Yes }\end{array}$ & $\begin{array}{l}\text { Yes } \\
\text { Yes }\end{array}$ & $\begin{array}{l}\text { Yes } \\
\text { Yes }\end{array}$ & $\begin{array}{l}\text { Yes } \\
\text { Yes }\end{array}$ & $\begin{array}{l}\text { Yes } \\
\text { Yes }\end{array}$ & $\begin{array}{l}\text { Yes } \\
\text { Yes }\end{array}$ & $\begin{array}{l}\text { Yes } \\
\text { Yes }\end{array}$ & $\begin{array}{l}\text { Yes } \\
\text { Yes }\end{array}$ & $\begin{array}{l}\text { Yes } \\
\text { Yes }\end{array}$ \\
\hline $\begin{array}{l}\text { Observation } \\
\text { s }\end{array}$ & 29 & 27 & 2779 & 2779 & 2779 & 2785 & 2780 & 2793 & 2787 & 2809 & 2780 & 2779 & 2796 & 2784 & 2764 & 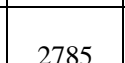 & 2813 & 2827 & 2779 & \\
\hline & 0.22 & 022 & 022 & 022 & 022 & 025 & 0.22 & 2170 & 2101 & 021 & 2700 & 211 & 023 & 2707 & 2707 & 022 & 2015 & 2021 & 2119 & \\
\hline
\end{tabular}

Standard enrors in brackets

* significant at $10 \%$;* significant at $5 \%$; *** significant at $1 \%$

Table A3-4

The input-output matrix used to calculate the regulation indicators in the downstream sectors - Period: 1995-2007

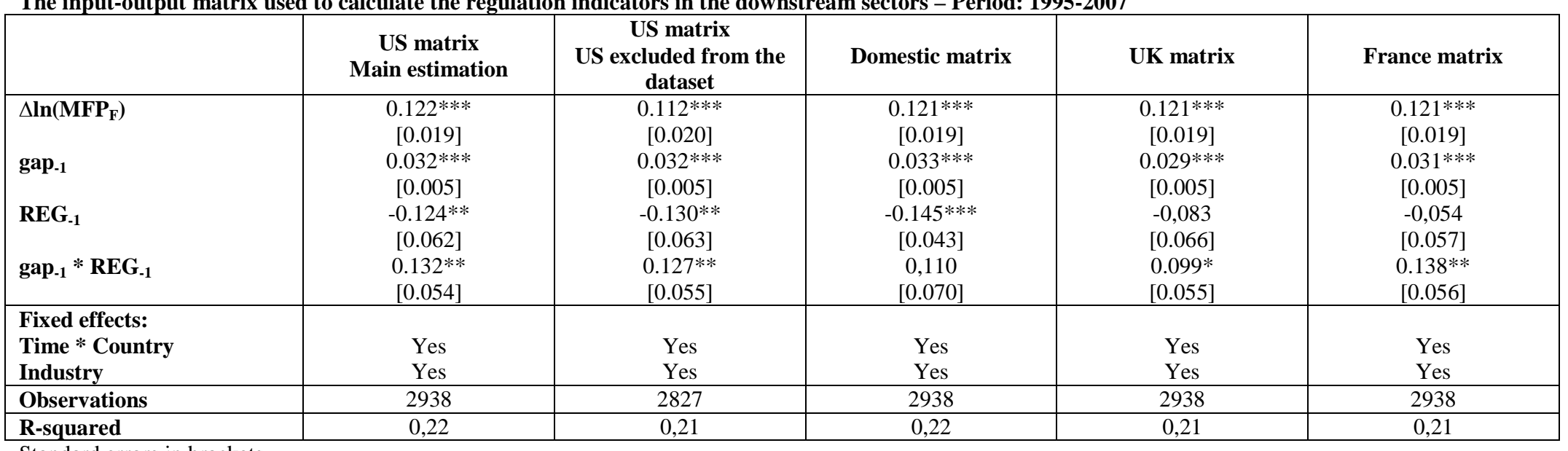

Standard errors in brackets

* significant at $10 \%$; ** significant at $5 \%$; ** significant at $1 \%$ 
Table A3-5

The price measurement of the output 'electrical and optical equipment' (30-33) - Period: 1995-2007

\begin{tabular}{|c|c|c|c|c|}
\hline & Main estimation & $\begin{array}{l}\text { 30-33 specific price is } \\
\text { retained for US }\end{array}$ & $\begin{array}{l}\text { US excluded from the } \\
\text { dataset }\end{array}$ & $\begin{array}{l}\text { US 30-33 specific } \\
\text { relative price is used } \\
\text { for all countries }\end{array}$ \\
\hline $\begin{array}{l}\Delta \ln \left(\mathbf{M F P}_{\mathrm{F}}\right) \\
\operatorname{gap}_{-1} \\
\text { REG }_{-1} \\
\operatorname{gap}_{-1} * \mathrm{REG}_{-1}\end{array}$ & $\begin{array}{c}0.122 * * * \\
{[0.019]} \\
0.032 * * * \\
{[0.005]} \\
-0.124 * * \\
{[0.062]} \\
0.132 * * \\
{[0.054]}\end{array}$ & $\begin{array}{c}0.108 * * * \\
{[0.021]} \\
0.022 * * * \\
{[0.004]} \\
-0.135 * * \\
{[0.064]} \\
0,073 \\
{[0.052]}\end{array}$ & $\begin{array}{c}0.110^{* * *} \\
{[0.019]} \\
0.032 * * * \\
{[0.005]} \\
-0.123 * * \\
{[0.062]} \\
0.128 * * \\
{[0.054]}\end{array}$ & $\begin{array}{c}0.129 * * * \\
{[0.022]} \\
0.034 * * * \\
{[0.005]} \\
-0.124 * \\
{[0.063]} \\
0.150^{* * *} \\
{[0.054]}\end{array}$ \\
\hline $\begin{array}{l}\text { Fixed effects: } \\
\text { Time * Country } \\
\text { Industry }\end{array}$ & $\begin{array}{l}\text { Yes } \\
\text { Yes }\end{array}$ & $\begin{array}{l}\text { Yes } \\
\text { Yes }\end{array}$ & $\begin{array}{l}\text { Yes } \\
\text { Yes }\end{array}$ & $\begin{array}{l}\text { Yes } \\
\text { Yes }\end{array}$ \\
\hline Observations & 2938 & 2938 & 2925 & 2938 \\
\hline R-squared & 0,22 & 0,21 & 0,21 & 0,21 \\
\hline
\end{tabular}

Standard errors in brackets

$*$ significant at $10 \% ; * *$ significant at $5 \%$; ** significant at $1 \%$

Table A3-6

PPP adjustment and MFP measurement- Period: 1995-2007

\begin{tabular}{|c|c|c|c|c|c|c|}
\hline & \multicolumn{2}{|c|}{ Main estimation } & \multicolumn{2}{|c|}{ Sectorial PPP } & \multicolumn{2}{|c|}{ "Structural productivity" } \\
\hline & 1985-2007 & 1995-2007 & 1985-2007 & 1995-2007 & 1985-2007 & 1995-2007 \\
\hline$\Delta \ln \left(\mathbf{M F P}_{\mathbf{F}}\right)$ & $\begin{array}{c}0.114 * * * \\
{[0.016]}\end{array}$ & $\begin{array}{c}0.122 * * * \\
{[0.019]}\end{array}$ & $\begin{array}{c}0.049 * * * \\
{[0.015]}\end{array}$ & $\begin{array}{c}0.037^{*} \\
{[0.019]}\end{array}$ & $\begin{array}{c}0,001 \\
{[0.018]}\end{array}$ & $\begin{array}{c}0,033 \\
{[0.021]}\end{array}$ \\
\hline $\operatorname{gap}_{-1}$ & $0.041 * * *$ & $0.032 * * *$ & $0.010 * * *$ & $0.007 * *$ & $0.027 * * *$ & $0.019 * * *$ \\
\hline & {$[0.004]$} & {$[0.005]$} & {$[0.002]$} & {$[0.003]$} & {$[0.003]$} & [0.004] \\
\hline REG $_{-1}$ & $-0,067$ & $-0.124 * *$ & $-0.085^{*}$ & $-0.112 *$ & $-0.133 * * *$ & $-0.158 * *$ \\
\hline & {$[0.047]$} & [0.062] & {$[0.049]$} & {$[0.066]$} & {$[0.051]$} & {$[0.064]$} \\
\hline $\operatorname{gap}_{-1} * \mathbf{R E G}_{-1}$ & $0.240 * * *$ & $0.132 * *$ & $0.081 * * *$ & 0,054 & $0.186 * * *$ & $0.104 * *$ \\
\hline & {$[0.040]$} & {$[0.054]$} & {$[0.029]$} & [0.038] & {$[0.036]$} & {$[0.047]$} \\
\hline Fixed effects: & & & & & & \\
\hline Time * Country & Yes & Yes & Yes & Yes & Yes & Yes \\
\hline Industry & Yes & Yes & Yes & Yes & Yes & Yes \\
\hline Observations & 2938 & 2938 & 4603 & 2922 & 4360 & 2888 \\
\hline R-squared & 0,22 & 0,26 & 0,22 & 0,19 & 0,24 & 0,2 \\
\hline
\end{tabular}

Standard errors in brackets

$*$ significant at $10 \%$;** significant at $5 \%$; ** significant at $1 \%$ 
Table A3-7

MFP measurement - Period: 1995-2007

\begin{tabular}{|c|c|c|c|c|c|}
\hline & Main estimation & MFP1 & MFP2 & MFP3 & MFP4 \\
\hline $\begin{array}{l}\Delta \ln \left(\mathrm{MFP}_{\mathrm{F}}\right) \\
\operatorname{gap}_{-1} \\
\text { REG }_{-1} \\
\operatorname{gap}_{-1} * \mathrm{REG}_{-1}\end{array}$ & $\begin{array}{c}0.122 * * * \\
{[0.019]} \\
0.032 * * * \\
{[0.005]} \\
-0.124 * * \\
{[0.062]} \\
0.132 * * \\
{[0.054]} \\
\end{array}$ & $\begin{array}{c}0.119 * * * \\
{[0.019]} \\
0.027 * * * \\
{[0.005]} \\
-0.126 * * \\
{[0.062]} \\
0.115 * * \\
{[0.052]} \\
\end{array}$ & $\begin{array}{c}0.118 * * * \\
{[0.019]} \\
0.027 * * * \\
{[0.005]} \\
-0.126 * * \\
{[0.062]} \\
0.077 \\
{[0.053]} \\
\end{array}$ & $\begin{array}{c}0.118 * * * \\
{[0.019]} \\
0.032 * * * \\
{[0.005]} \\
-0.125 * * \\
{[0.062]} \\
0.115 * * \\
{[0.056]} \\
\end{array}$ & $\begin{array}{c}0.117 * * * \\
{[0.019]} \\
0.033 * * * \\
{[0.005]} \\
-0.127 * * \\
{[0.063]} \\
0.124 * * \\
{[0.057]} \\
\end{array}$ \\
\hline $\begin{array}{l}\text { Fixed effects: } \\
\text { Time * Country } \\
\text { Industry }\end{array}$ & $\begin{array}{l}\text { Yes } \\
\text { Yes }\end{array}$ & $\begin{array}{l}\text { Yes } \\
\text { Yes }\end{array}$ & $\begin{array}{l}\text { Yes } \\
\text { Yes }\end{array}$ & $\begin{array}{l}\text { Yes } \\
\text { Yes }\end{array}$ & $\begin{array}{l}\text { Yes } \\
\text { Yes }\end{array}$ \\
\hline Observations & 2938 & 2887 & 2895 & 2925 & 2919 \\
\hline R-squared & 0.22 & 0.21 & 0.21 & 0.21 & 0.22 \\
\hline
\end{tabular}

Standard errors in brackets

* significant at $10 \%$; ** significant at $5 \%$; *** significant at $1 \%$

MFP1: The labour share in the value added is country*sector*year specific

MFP2: The labour share in the value added is country*sector specific, and calculated for each country*sector by an average on 1984-2007

MFP3: The labour share in the value added is sector*year specific and is, for each sector*year, the one observed in the US

MFP4: The labour share in the value added is sector specific and is, for each sector, the average of the one observed in US on 1984-2007 
Table A3-8

Productivity measurement: Labour productivity (LP) or MFP

\begin{tabular}{|c|c|c|c|c|c|c|}
\hline & Main estimation & (2) & (3) & (4) & (5) & (6) \\
\hline$\Delta \ln \left(\mathbf{M F P}_{\mathrm{F}}\right)$ or $\Delta \ln \left(\mathbf{L} \mathbf{P}_{\mathrm{F}}\right)$ & $0.122 * * *$ & $0.126^{* * * *}$ & $0.057 * * *$ & $0.055^{* * *}$ & $0.054 * *$ & $0.093 * * *$ \\
\hline gap $_{1}$ & $0.032 * * *$ & $0.033 * * *$ & $0.031 * * *$ & $0.016 * * *$ & $0.022 * * *$ & $0.011 * * *$ \\
\hline & {$[0.005]$} & {$[0.005]$} & {$[0.005]$} & {$[0.005]$} & {$[0.005]$} & {$[0.004]$} \\
\hline REG $_{-1}$ & $-0.124 * *$ & -0.079 & -0.078 & $-0.133 * *$ & -0.102 & $-0.230 * * *$ \\
\hline & [0.062] & [0.064] & [0.064] & [0.066] & [0.068] & [0.064] \\
\hline $\operatorname{gap}_{-1} *$ REG $_{-1}$ & $0.132 * *$ & $0.133 * *$ & $0.129 * *$ & -0.108 & -0.085 & $0.091 *$ \\
\hline & [0.054] & {$[0.056]$} & [0.057] & [0.066] & [0.068] & [0.051] \\
\hline$\Delta(\mathbf{K} / \mathbf{L})$ & & $\begin{array}{c}0.366^{* * *} * \\
{[0.027]}\end{array}$ & $\begin{array}{c}0.361 * * * \\
{[0.027]}\end{array}$ & $\begin{array}{c}0.338 * * * \\
{[0.028]}\end{array}$ & & \\
\hline Fixed effects : & & & & & & \\
\hline Time * Country & Yes & Yes & Yes & Yes & Yes & Yes \\
\hline Industry & Yes & Yes & Yes & Yes & Yes & Yes \\
\hline Productivity measurement : & & & & & & \\
\hline$\Delta \ln \left(\mathbf{M F P}_{\mathrm{F}}\right)$ & TFP & TFP & LP & LP & LP & LP \\
\hline $\operatorname{gap}_{-1}$ & TFP & TFP & TFP & LP & LP & LP \\
\hline Observations & 2938 & 2794 & 2794 & 2794 & 2794 & 4686 \\
\hline R-squared & 0.22 & 0.28 & 0.27 & 0.27 & 0.22 & 0.18 \\
\hline
\end{tabular}

The sample is smaller in estimations 2-5, than in the main estimation. This is because the leading country-industry pairs in each period are not the same if productivity is measured by MFP or LP. Observations before the entrance or after the exit of leaders are dropped to avoid spurious changes in gap and $\Delta \ln \left(\mathrm{MFP}_{\mathrm{F}}\right)$ and their number differs depending on the definition of productivity. Available observations for LP are many more than for MFP (whose construction which require capital stock data) as reflected in column 6. Column 5 replicates the same regression on the same number of observations as in columns 2-4 for comparison purposes.

Standard errors in brackets

* significant at $10 \% ; * *$ significant at $5 \% ; * * *$ significant at $1 \%$ 